\title{
Market Structure and Media Diversity ${ }^{1}$
}

\author{
Scott J. Savage, Donald M. Waldman, Scott Hiller \\ University of Colorado at Boulder \\ Department of Economics \\ Campus Box 256 \\ Boulder, CO 80309-0256
}

\begin{abstract}
We estimate the demand for local news service described by the offerings from newspapers, radio, television, the Internet, and Smartphone. The results show that the representative consumer values diversity in the reporting of news, more coverage of multicultural issues, and more information on community news. About two-thirds of consumers have a distaste for advertising, which likely reflects their consumption of general, all-purpose advertising delivered by traditional media. Demand estimates are used to calculate the impact on consumer welfare from a marginal decrease in the number of independent television stations that lowers the amount of diversity, multiculturalism, community news, and advertising in the market. Welfare decreases, but the losses are smaller in large markets. For example, small-market consumers lose \$53 million annually while large-market consumers lose $\$ 15$ million. If the change in market structure occurs in all markets, total losses nationwide would be about $\$ 830$ million.
\end{abstract}

September 25, 2012

Key words: market structure, media diversity, mixed logit, news, welfare

JEL Classification Number: C9, C25, L13, L82, L96

\footnotetext{
${ }^{1}$ The Federal Communications Commission (FCC) and the Time Warner Cable (TWC) Research Program on Digital Communications provided funding for this research. We are grateful to Jessica Almond, Fernando Laguarda, Jonathan Levy, and Tracy Waldon for their assistance during the completion of this project. Yongmin Chen, Nicholas Flores, Jin-Hyuk Kim, David Layton, Edward Morey, Gregory Rosston, Bradley Wimmer, and seminar participants at the University of California, University of Colorado, SUNY and attendees at the Conference in Honor of Professor Emeritus Lester D. Taylor at Jackson Hole provided helpful comments and contributions. Any opinions expressed here are those of the authors and not those of the FCC or TWC.
} 


\section{INTRODUCTION}

Information on news and current affairs can raise political awareness and promote a range of ideas. With the assumption that unregulated media markets supply too little variety, many societies have charged regulators with ensuring there are sufficient opportunities for different, new, and independent viewpoints (which we shall refer to as "diversity" below), and that media respond to the interests of their local communities ("localism"). In the U.S., the Federal Communications Commission (FCC) has traditionally limited the amount of commonand cross-ownership of newspapers, radio and television (TV) stations. Recently, the FCC relaxed ownership rules and refocused their attention on market forces; for example, consumer preferences and new media, such as satellite, the Internet, and Smartphone, in order to deliver their diversity and localism goals. Given the increase in choices through new media, supporters of greater ownership concentration argue that traditional media should be free to consolidate and use the efficiencies to provide more diverse and local news programming. Opponents question whether such efficiencies are achievable, and argue that large, consolidated media corporations are not flexible enough to serve the interests of local and minority communities.

Evaluation of these arguments requires, among other things, measurement of the expected societal benefits that arise from increased media diversity and localism, and how these benefits change with regulatory interventions that shape media market structure. In this paper, we estimate consumer preferences for their local news and current affairs service ("news service") described by the offerings from newspapers, radio, TV, the Internet, and Smartphone. News service characteristics are diversity of opinion in the reporting of information, coverage of multiculturalism issues, amount of information on community news and events, and amount of space or time devoted to advertising. We use our demand estimates to calculate the impact on 
consumer welfare from a change in media market structure that reduces the number of independent TV stations in the market. Specifically, we employ the willingness-to-pay (WTP) construct to measure the welfare effects between the news service supplied to the consumer before the change in market structure and the service supplied after the change. We focus on broadcast TV stations because they are the main source of news for most households and because the FCC has direct oversight of their ownership structure. ${ }^{2}$ By relating consumer valuations of news service to a measure of TV market structure, it is possible to indirectly assess the extent to which ownership rules address the policy goals of diversity and localism.

We estimate our demand model with discrete choice data obtained from a nationwide survey of U.S. households during March, 2011. Results show that diversity of opinion, community news, and advertising are important characteristics of local news services. The representative consumer is willing to pay from $\$ 21$ to $\$ 25$ per month for an increase in diversity of opinion (and approximately the same for community news) from a low to a medium level (defined in Table 1), but only an additional $\$ 6$ to $\$ 7$ to move to a high level of diversity of opinion (or community news). The representative consumer also values an improvement in information that reflects the interests of women and minorities from low to medium (\$7) more than an improvement from low to high (\$4). Many consumers have a distaste for advertising, which likely reflects their consumption of general, all-purpose advertising from traditional media such as radio and TV. The representative consumer is willing to pay about $\$ 5$ to avoid a movement from a low to a medium level of advertising, but the much higher amount of $\$ 17$ to avoid a movement from a medium to a high level.

\footnotetext{
${ }^{2}$ At 2010, 58 percent of the public turned on the TV for news, 44 percent used the Internet or their cellular telephone, 34 percent turned on the radio, and 31 percent read the newspaper (Pew Research Center; 2010).
} 
Using FCC (2011) data on media market structure, we present evidence that indicates the amount of diversity, localism, and advertising in the news services supplied to consumers is lower following a marginal decrease in the number of independent TV stations. As a result, the average "small market" (i.e., five or fewer TV stations) consumer loses $\$ 0.99$ per month, whereas the average "large market" (i.e., 20 or more TV stations) consumer loses $\$ 0.44$ per month. These losses are equivalent to $\$ 53$ million annually for all small-market households in the U.S. and $\$ 15$ million for large-market households. If the change in market structure occurs in all markets, aggregate losses nationwide would be about $\$ 830$ million.

Other studies have measured the relationship between information on news and current affairs and market structure. However, these studies measure supply from just one of the media sources that comprise the consumer's news service; for example, Milyo (2007), Gentzkow (2007) and Gentzkow and Shapiro (2010) for newspapers, and Siegelman and Waldfogel (2001) and Crawford (2007) for radio and TV. Our research is also related to studies that quantify the relationship between quality and market structure for different industries. For example, Mazzeo (2003) shows that average flight delays are longer in more concentrated airline markets. Goolsbee and Petrin (2004) estimate that cable TV channel capacity, number of over-the-air channels and number of premium movie channels increased in response to satellite entry. Matsa (2011) finds that supermarkets facing more intense competition have more products available on their shelves, while Olivares and Cachon (2009) show that the inventories of General Motors dealerships increases with the number of competitors. In contrast, Domberger and Sherr (1989) find no correlation between the threat of new entry and customer's satisfaction with their attorney used for home purchases. ${ }^{3}$ Because we measure the

\footnotetext{
${ }^{3}$ Some papers exploit a law or regulatory change to document the effect of a change in market structure on the supply of media and telecommunications services. Berry and Waldfogel (2001) show that, following the
} 
change in market structure by reducing the number of independent TV stations, our paper is also related to structural models of differentiated oligopoly that predict the price effects from a simulated merger. For example, Nevo (2000) for breakfast cereals, Pinske and Slade (2004) for U.K. brewing, and Ivaldi and Verboven (2005) for car manufacturing.

Relative to these literatures our study makes several contributions. First, we offer new evidence from media markets by examining the welfare effects from a news service bundled from newspapers, radio, TV, the Internet, and Smartphone. Second, the prediction of non-price effects appears to be novel in the simulated merger literature. Finally, by looking at a vector of non-price effects we are able to document a new and interesting tradeoff between the diversity and localism characteristics of news service, and advertising. That is, the amount of diversity and localism declines following a decrease in the number of independent TV stations, which is a cost to the typical consumer, but so too does the amount of advertising, which is a benefit to the typical consumer. This finding should be interesting to antitrust officials and policy makers because it highlights an additional potential benefit for consideration during the analysis of a media market merger. It also provides a new angle from which to assess the efficacy of media ownership rules.

The remainder of this paper is organized as follows. Section 2 outlines the empirical model. Data are described in Section 3. Section 4 presents demand estimates and calculates consumer valuations for the diversity, localism and advertising characteristics of a news service. Section 5 presents estimates of the impact on consumer welfare from a change in market structure, and Section 6 concludes.

Telecommunications Act of 1996 (“Act”), consolidation reduced radio station entry and increased product variety. Economides et al. (2008) show that following the Act, households benefited more from the new plan and quality differences offered by entrants into local telephone markets than from price decreases. 


\section{EMPIRICAL MODEL}

We examine the relationship between market structure and media diversity by asking two questions: what are the expected societal benefits that arise from increased media diversity and localism, and how do these benefits change with regulatory interventions that shape media market structure? We employ a three-step empirical approach to answer these questions. In step one we estimate a mixed logit model of the demand for local news service with discrete choice data. The estimated preferences from the representative household's utility function are used to calculate consumer's WTP for each of the non-price characteristics of their news service. In step two we estimate the relationship between the number of TV stations in the market and the amount of diversity, localism and advertising supplied within each household's news service with data from the FCC (2011). In step three, we use the estimated demand and supply response parameters from steps one and two, respectively, to calculate the impact on consumer welfare from a change in media market structure that reduces the number of independent TV voices by one.

\subsection{Step one: the demand for news services}

There are several problems when estimating demand for news service with market data. First, households consume a bundle of entertainment and news services from the offerings from newspapers, radio, TV, the Internet, and Smartphone, but data on these bundles, their non-price characteristics and prices are not readily available. Second, even when available, these data are unlikely to exhibit sufficient variation for the precise estimation of demand parameters. For example, the levels for the diversity and localism characteristics are often highly, positively correlated. Third, news services are a mixture of private and public goods and many households, 
e.g., those who bundle broadcast radio and TV stations, make no direct payment for consumption. Because detailed data on the amount of advertising within household bundles are not available, it is not possible to accurately measure the full cost of news services.

We overcome these problems by using an indirect valuation method, similar to that used in the environmental and transportation choice literature, that employs market and experimental data. The market data is the news service households currently consume. The experimental data is a set of constructed news services. We design a choice set that manipulates the characteristics of the constructed news services to obtain the optimal variation in the data needed to estimate the demand parameters precisely. Respondents choose between a pair of constructed news services, and then between that choice and their actual news service at home. Because our design exogenously determines the levels of the characteristics of each news service, and randomly assigns the levels across respondents, we limit measurement and collinearity problems. Furthermore, by asking respondents to complete eight such choice occasions, we increase parameter estimation precision, and reduce sampling costs by obtaining more information on preferences for each respondent.

The conditional indirect utility function for household $n$ from news service alternative $j$ on choice occasion $t$ is assumed to be:

$$
U_{n j t}^{*}=\beta_{n}^{\prime} x_{n j t}+\xi_{n j t}+\varepsilon_{n j t}
$$

where $\beta_{n}$ is a vector of consumer-specific marginal utility coefficients, $x_{n j t}$ is a vector of observed non-price and price characteristics of entertainment and news service, $\xi_{n j t}$ is the utility from unobserved entertainment services and from other dimensions of news not included in $x_{n j t}$, and $\varepsilon_{n j t}$ is an unobserved random error term that is independently and identically distributed 
extreme value. The density of the distribution for $\beta_{n}$ is $f\left(\beta_{n} \mid \theta\right)$ with $\theta$ measuring the mean and covariance parameters of $\beta_{n}$. Assuming $\beta_{n}=b+\eta_{n}$, utility can be re-written as:

$$
U_{n j t}^{*}=b^{\prime} x_{n j t}+\eta_{n}^{\prime} x_{n j t}+\xi_{n j t}+\varepsilon_{n j t}
$$

where $b$ is the population mean marginal utility and $\eta_{n}$ is the individual consumer's deviation from this mean. Given $\varepsilon$ is distributed extreme value, and assuming an appropriate distribution for $\beta_{n}$, mixed logit estimation of equation 2 is possible by simulated maximum likelihood (Revelt and Train, 1998; Brownstone and Train, 1999). In our choice scenario described in Section 3, the consumer chooses between three alternatives in each choice occasion that differ in their levels of $x_{n j t}$ only. By holding all other dimensions of entertainment and news services in equation 2 constant so that $\xi_{n j t}=\xi_{n}$, the model controls for potential correlation between price and quality that is not observed by the researcher.

Table 1 describes the levels of the characteristics that comprise the elements of the vector $x_{n j t}$ DIVERSITY OF OPINION is the extent to which the information on news and current affairs in the household's news service reflects different viewpoints.

MULTICULTURALISM is the amount of information on news and current affairs in the household's news service that reflects the interests of women and minorities. COMMUNITY NEWS is the amount of information on community news and events in the household's news service. ADVERTISING is the amount of space and/or time devoted to advertising in the household's news service. COST is the dollar amount the household pays per month for their news service. That is, the total of monthly subscriptions to all media sources, plus any contributions to public radio or public TV stations.

Since they do not have an understandable metric, it is convenient to convert the estimated marginal utilities for changes in $x_{n j t}$ into WTP. For example, the WTP for a one unit 
increase in diversity of opinion $\left(W T P_{d}\right)$ is defined as how much more the news service would have to be priced to make the consumer just indifferent between the old (cheaper but with only one viewpoint) service and the new (more expensive but with a few different viewpoints) service. This can be calculated from our estimates as:

$$
W T P_{d}=-\beta_{2} / \beta_{1}
$$

where $\beta_{1}$ is the marginal disutility of COST and $\beta_{2}$ is the marginal utility of DIVERSITY OF OPINION. ${ }^{4}$ This approach to estimating consumer valuations is used for all other non-price characteristics of local news service.

2.2 Step two: the supply of news services

Previous studies of media markets typically use academic and industry databases from BIA Financial Networks, Neilson Media Research and ProQuest Newsstand to measure the quantity and quality of news provided by newspapers, radio and TV stations. For example, Yan and Napoli (2006) and Crawford (2007) count the minutes of local programming provided by TV stations, while Gentzkow and Shapiro (2010) measure diversity with an index that measures the similarity of a newspaper's language to that of a congressional Republican or Democrat. Because we are investigating a household's news services from all of their media sources, similar measures are not practical for this study. Instead, we use information on consumer's news service at home to measure the characteristics supplied by news service alternatives in different TV markets.

\footnotetext{
${ }^{4}$ The discrete-choice model actually estimates $\beta_{2} / \sigma$ and $\beta_{l} / \sigma$, where $\sigma$ is the scale parameter. The WTP calculation is not affected by the presence of the scale parameter because $-\left(\beta_{2} / \sigma\right) /\left(\beta_{l} / \sigma\right)=-\beta_{2} / \beta_{l}$.
} 
Consider a reduction in the number of independent TV voices in a market as it impacts the single news service characteristic diversity of opinion $(d)$. A simple representation of the diversity of opinion produced by alternative $j$ for consumer $n$ in television market $m$ is:

$$
d_{n j m}^{*}=\delta_{1} \text { VOICES }_{m}+\delta_{2} \text { STATIONS }_{m}+\delta_{3}\left(\text { VOICES }_{m} \times \text { STATIONS }_{m}\right)+\varphi Y_{n}+\gamma Z_{j}+v_{n j m}
$$

where $d_{n i m}^{*}$ is the unobserved continuous index of respondent $n$ 's diversity of opinion characteristic, $V O I C E S_{m}$ is the number of independent TV voices in the market, STATIONS $_{m}$ is the number of TV stations in the market, $Y_{n}$ is a vector of consumer-specific demographic controls, $Z_{j}$ is a vector of news service controls, the $\delta$ 's, $\varphi$ and $\gamma$ are parameters to be estimated, and $v$ is an independently and identically normally distributed error term with zero mean and constant variance $\sigma_{v}{ }^{2}$. The interaction term is included to measure the different impacts from a change in market structure in small- versus large-TV markets.

The respondent reports one of three possible levels for the diversity of opinion feature, low, medium or high, based upon her or his level of $d_{n j m}^{*}$ :

$$
d_{n j m}=\left\{\begin{array}{c}
\text { low } d_{n j m}^{*} \leq 0 \\
\text { medium } 0<d_{n j m}^{*} \leq \mu \\
\text { high } \mu<d_{n j m}^{*}
\end{array}\right.
$$

where $\mu$ is the normalized unknown level of $d_{n i m}^{*}$ above which respondents report a high level for diversity of opinion. Given $v$ is normally distributed, equation's 4 and 5 represent the conventional ordered probit model, which can be estimated by maximum likelihood (Zavoinia and McElvey, 1975). We estimate equation 4 to obtain the relationships between the number of TV stations in the market and the four non-price characteristics of news service, and use these estimates to approximate the supply-side responses from media outlets. 
2.3 Step three: estimating consumer benefits from a change in market structure

It is tempting to multiply the estimated $\delta_{1}$ and $\delta_{3}$ from equation 4 by the estimated $\beta_{2}$

from equation 2 , to calculate the value to society from a change in the number of independent TV voices that affects the market's provision of diversity of opinion. However, this would

result in an estimate of $\frac{\beta_{2}}{\sigma} \cdot \frac{\delta_{1}+\delta_{3} \text { STATIONS }_{m}}{\sigma_{v}}$, where $\sigma_{v}$ is the standard deviation of the errors in equation 4 , and not the actual effect that we are interested in. The problem is that we cannot observe the scale of diversity of opinion. Instead, we apply a new technique to our estimates, explained below, which takes advantage of the fact that we do not need to estimate the scale of diversity of opinion. This alternative approach uses our sample estimates from equations 2 and 4 to predict how changes in the number of independent TV voices affect consumer's expected benefit from the amount of diversity of opinion supplied in their local news service.

For ease of notation, we let $X=$ VOICES and drop all subscripts that indicate consumers, alternatives, markets, etc. The representative consumer's expected benefit from the diversity of opinion in their local news service is:

$$
E\left[B_{d}(X)\right]=P_{d L}(X) b_{d L}{ }^{*}+P_{d M}(X) b_{d M}{ }^{*}+P_{H}(X) b_{d H}{ }^{*}
$$

where $P_{d L}(X)$ is the probability that the consumer will be in the low diversity of opinion state, $P_{d M}(X)$ is the probability that the consumer will be in the medium state, $P_{d H}(X)$ is the probability that the consumer will be in the high state, and $b_{d L}{ }^{*}, b_{d M}{ }^{*}$ and $b_{d H}{ }^{*}$ are consumer valuations for low, medium and high diversity of opinion.

We do not observe $b_{d L}{ }^{*}, b_{d M}{ }^{*}$ and $b_{d H}{ }^{*}$. However, we are able to estimate from step one the consumer's WTP for a change from low to medium diversity of opinion $\left(\Delta b_{d M}\right)$, and the WTP for a change from low to high diversity $\left(\Delta b_{d H}\right)$. Writing $b_{d M}{ }^{*}=b_{d L}{ }^{*}+\Delta b_{d M}$ and substituting this expression into the consumer's expected benefit equation 6 gives 
$E\left[B_{d}(X)\right]=P_{d L}(X) b_{d L}{ }^{*}+P_{d M}(X)\left(b_{d L}{ }^{*}+\Delta b_{d M}\right)+P_{d H}(X)\left(b_{d L}{ }^{*}+\Delta b_{d H}\right)$. The effect of a change in $X$ on the expected benefit from diversity of opinion is:

$$
\begin{aligned}
\frac{\Delta E\left[B_{d}(X)\right]}{\Delta X} & =\frac{\Delta P_{d L}}{\Delta X} b_{d L}{ }^{*}+\frac{\Delta P_{d M}}{\Delta X}\left(b_{d L}{ }^{*}+\Delta b_{d M}\right)+\frac{\Delta P_{d H}}{\Delta X}\left(b_{d L}{ }^{*}+\Delta b_{d H}\right) \\
& =\left(\frac{\Delta P_{d L}}{\Delta X}+\frac{\Delta P_{d M}}{\Delta X}+\frac{\Delta P_{d H}}{\Delta X}\right) b_{d L}{ }^{*}+\frac{\Delta P_{d M}}{\Delta X} \Delta b_{d M}+\frac{\Delta P_{d H}}{\Delta X} \Delta b_{d H} \\
& =\frac{\Delta P_{d M}}{\Delta X} \Delta b_{d M}+\frac{\Delta P_{d H}}{\Delta X} \Delta b_{d H}
\end{aligned}
$$

where $\frac{\Delta P_{d M}}{\Delta X}$ and $\frac{\Delta P_{d H}}{\Delta X}$ measure the effects of a change in $X$ on the predicted probability of being in the medium and the high diversity of opinion states, and $\frac{\Delta P_{d L}}{\Delta X}+\frac{\Delta P_{d M}}{\Delta X}+\frac{\Delta P_{d H}}{\Delta X}=0$, which follows from the requirement that the three probabilities sum to one. The derivation of this result shows clearly that the change in expected consumer welfare is a function of only WTP for a change out of the low level of diversity and the changes in probability for the supply of medium and high levels of diversity.

Equation 7 provides the basis for calculating the value to society from a change in market structure that affects the provision of diversity of opinion in local media markets. Estimates of $\Delta b_{d M}$ and $\Delta b_{d H}$ for the typical consumer are obtained from the demand estimates and marginal WTP calculations in step one. Estimates of $\frac{\Delta P_{d M}}{\Delta X}$ and $\frac{\Delta P_{d H}}{\Delta X}$ for each individual consumer are obtained from the ordered probit model of media supply responses in step two. In step three, we use our estimated coefficients from the ordered probit model and the sample data to calculate the predicted probability distributions for low, medium and high diversity of opinion in the "before" environment. Holding all other things constant, we then reduce the number of independent TV voices by one in the sample data to approximate the change in market structure, and re-calculate the predicted probability distributions for low, medium and 
high diversity of opinion in the "after" environment. The difference in before-and-after predicted probabilities are used to form the change in probabilities, $\frac{\Delta P_{d M}}{\Delta X}$ and $\frac{\Delta P_{d H}}{\Delta X}$. These calculations are repeated for the multiculturalism, community news, and advertising characteristics of news service, and then aggregated to reflect the general population.

\section{DATA}

\subsection{Experimental design}

The WTP for local media environment features are estimated with data from an online survey questionnaire employing repeated discrete-choice experiments. The questionnaire begins with the cognitive buildup section that describes the respondent's local news service in terms of the offerings from newspapers, radio, TV, the Internet, and Smartphone. Respondents are asked questions about their media sources, how much information they consume from each source, the cost of their media sources, and the levels of the four different characteristics of their news service described in Table $1 .^{5}$

Cognitive buildup is followed by the choice scenario. Information from the cognitive buildup questions is used to summarize each respondent's actual entertainment and news service at home with respect to their media sources, the levels of the non-price characteristics of their service, DIVERSITY OF OPINION, MULTICULTURALISM, COMMUNITY NEWS and ADVERTISING, and their COST. A table summarizing the sources and characteristics of the respondent's actual media environment at home is presented before the choice scenario. The respondent is then instructed to answer eight choice occasions. In each occasion, they choose

\footnotetext{
${ }^{5}$ Respondents were asked to consider what is available in their local media environment, rather than what they usually view or listen to. This represents a statement about the amount and quality of information programming being produced by media sources for their consumption.
} 
between their actual news service at home and two constructed new service alternatives, labeled A and B, that differ by their levels of DIVERSITY OF OPINION, MULTICULTURALISM, COMMUNITY NEWS, ADVERTISING and COST.

We used market data from newspapers, radio and TV stations, Internet and mobile telephone service providers, a pilot study and three focus groups to test and refine our descriptions of the characteristics for news service alternatives (See Savage and Waldman 2011 - for more discussion). Measures developed by Huber and Zwerina (1996) were used to generate an efficient non-linear optimal design for the levels of the constructed news characteristics. A fractional factorial design created 72 paired descriptions of A and B news services that were grouped into nine sets of eight choice questions. The nine choice sets were rebalanced to ensure that each household faced a range of costs that realistically portrayed the prices for media sources in their local market. For example, a respondent who indicated that they pay nothing for their news source was exposed to a range of costs that included zero dollars per month. ${ }^{6}$ The nine choice sets, along with the order of the eight A-B pair choice alternatives within each choice set, were randomly distributed across all respondents.

\subsection{Survey administration}

Knowledge Networks Inc. (KN) administered the online survey. Panel members are recruited through national random samples, almost entirely by postal mail. For incentive, they are rewarded with points for participating in surveys, which can be converted to cash or other rewards. ${ }^{7}$ During the week of March 7, 2011, KN randomly contacted a gross sample of 8,621

\footnotetext{
${ }^{6}$ Upon completion of their cognitive buildup questions, an online algorithm calculated each individual's total cost of their local entertainment and news service and assigned the appropriate cost range for their choice occasions. ${ }^{7} \mathrm{KN}$ recruitment uses dual sampling frames that includes both listed and unlisted telephone numbers, telephone and non-telephone households, and cellphone-only households, as well as households with and without Internet
} 
panel members to inform them about the survey. The survey was fielded from March 11 to March 21. A total of 5,548 respondents from all 50 states and the District of Columbia completed survey questionnaires. Because of incomplete survey responses, we trimmed the sample by 417 respondents. The median completion time for our sample of 5,131 respondents with complete information was about 16 and three-quarter minutes.

Table 2 presents a selection of demographics for the U.S. population, for all KN's panel members, and for panel members who were invited to participate in this survey (United States Census Bureau, 2009; Knowledge Networks, Inc., 2010). The demographics for all KN panel members are similar to those reported by the Census Bureau. Casual inspection of column four and column five of Table 2 also show that, apart from race and employment status, the demographics for the gross sample of panel members invited to participate in this study and the final sample of respondents who completed questionnaires are also similar to those reported by the Census Bureau. However, estimates from the probit model that compares respondent's characteristics between the gross sample and the final sample also indicate potential differences in age, gender, education, and Internet access between our final sample and the population. We remedy this possible source of bias in our results from step one and step two by estimating with weighted maximum likelihood. See Savage and Waldman (2011) for the probit model estimates and the procedures used to develop the post-stratification weights.

\subsection{Media sources and news service}

Table 3 presents summary statistics for respondent's media sources. Columns two and three show that about 94 percent of sample respondents watch TV, 81 percent listen to the 
radio, and 80 percent use the Internet. About 45 percent of respondents read a paper or online newspaper regularly, and 24 percent of sample respondents own a Smartphone. ${ }^{8}$ On average, TV viewers spend about 1.9 hours on a typical day watching TV to get information on news and current affairs, radio listeners spend 1.4 hours listening to the radio to get information on news and current affairs, and Internet users spend one hour online (e.g., MSN, Yahoo, radio and TV station web sites, journalists' blogs) to get information on news and current affairs. Newspaper readers also spend about one hour on a typical day reading the newspaper, while Smartphone owners use their phone to go online for 0.6 hours to get information on news and current affairs online. The most popular media source combinations are radio, TV and the Internet, about 30 percent of sample respondents, and newspaper, radio, TV and the Internet, about 26 percent of sample respondents.

Summary statistics for news service characteristics are presented in Table 4. These data indicate that, on average, the levels of the DIVERISTY OF OPINION, MULTICULTURALISM, COMMUNITY NEWS and ADVERTISING characteristics were about "medium." About 58 percent of respondents indicated that they bundled their subscription TV service with the Internet and/or telephone service. The price (or, COST) for the typical media combination ranged from zero to $\$ 447$ per month, with an average of $\$ 111.20$ per month. Interestingly, about ten percent of the sample indicated that they have contributed $\$ 117$, on average, to public radio and/or TV stations during the past twelve months. This is reasonably close to the combined annual costs of membership at 2011. For example, Rocky Mountain PBS offers an annual membership for $\$ 40$ and Colorado Public Radio for $\$ 120$. These membership costs vary between states.

\footnotetext{
${ }^{8}$ Complementary data from the Neilson Company (2010) and the U.S. Census Bureau (2011) indicate that about 93 percent of persons watch TV, 82 percent listen to the radio, and 77 percent use the Internet. About 67 percent of respondents read a newspaper regularly, and 25 percent of sample respondents own a Smartphone.
} 
Because they are self-reported, there may be some concern about the accuracy of the data describing the news service characteristics in our sample. We alleviate these concerns by testing the relationships between our measures of diversity and localism and alternative measures from the FCC (2011) and Gentzkow and Shapiro (2010). Table 5 reports the estimates from a simple ordered-probit model of DIVERISTY OF OPINION, MULTICULTURALISM or COMMUNITY NEWS, on these various alternative measures of diversity and localism for radio, TV and newspapers. In general, the evidence indicates that the information reported by survey respondents is a reasonably good proxy for the diversity of news service alternatives in U.S. markets. For example, columns one and two show a positive correlation between the number of TV stations broadcasting multiple channels and DIVERSITY OF OPINION, positive correlations between the number of non-commercial radio and TV stations and DIVERSITY OF OPINION, and a positive correlation between the number of different radio formats and DIVERSITY OF OPINION. Column three shows a negative correlation between the Gentzkow-Shapiro measure of newspaper slant and DIVERSITY OF OPINION. Columns four and five show positive correlations between the number of stations with female or minority ownership and MULTICULTURALISM. Columns six and seven show negative, albeit insignificant, relationships between the number of stations with non-local ownership and COMMUNITY NEWS.

\subsection{Market structure}

We use data from the FCC (2011) to measure media market structure. The important variables of interest are the number of full-power independent TV stations in the market (VOICES) and the total number of full-power independent and non-independent TV stations in 
the market (STATIONS). VOICES is measured by first combining all the TV outlets within each market. The listing of the unique parent company identifiers of all attributable owners of an outlet ("voiceprint") is then created, sorted alphabetically, and duplicate voiceprints are eliminated. The parent identifier is then used to count the number of voices in the voiceprint for each outlet. Voiceprints composed of a single voice are added to the voice count of the market, while any voiceprint that includes one of the voices counted at the previous stage of the calculation are eliminated. These are voices that are not independent because their voice has been heard on another outlet. This process is sequentially repeated based on the number of voices in the voiceprint. Table 6 describes the remaining market structure variables considered in this analysis.

Table 7 presents summary statistics. Our sample covers 203 of the nation's 210 television markets. ${ }^{9}$ As of December, 2009, the total number of newspaper, radio, and TV outlets ranged from four to 291, with an average of 139 per market. On average, about 81 percent of media outlets are radio stations, which partially reflects the geographical definition of a TV market which can include several radio markets. When examining the market structure data at the $75^{\text {th }}$ percentile, we observe that most markets are served by about 182 or fewer media outlets. The bottom panel in Table 6 shows a similar pattern for small TV markets with five or fewer stations. At December, 2009, the total number of newspaper, radio and TV outlets in small markets ranged from four to 86 , with an average of 47 per market. On average,

\footnotetext{
${ }^{9}$ Television Market Area or "market" is a geographical region where all households receive the same offerings from TV stations. The seven markets outside our sample are: Bend, OR; Fairbanks, AK; Grand Junction, CO; Missoula, MT; North Platte, NE; Ottumwa, IA - Kirksville, MO; and Presque, ME. All seven are small markets with five or fewer TV stations. As shown in Table 6, the remaining small markets in our sample cover 8.43 percent of households. FCC (2011) data show that 8.37 percent of population households were in small markets at December, 2009.
} 
about 82 percent of media outlets in small markets are radio stations, and as indicated by the $75^{\text {th }}$ percentile, most small markets are served by about 57 or fewer media outlets.

The survey provided the household data used to construct the control variable vectors $Y_{n}$ and $Z_{j}$ in supply equation 4 . The $Y$ vector measures the head of the household's age ( $A G E=1$ if $18-24$ years; 2 if $25-34 ; 3$ if $35-44 ; 4$ if $45-54 ; 5$ if $55-64 ; 6$ if $65-74 ; 7$ if 75 years or over), education $(E D U C=1$ if less than high school; 2 if high school; 3 if some college; 4 if bachelor's degree or more), gender (GENDER = 1 if female; 0 otherwise), household income $(I N C O M E=1$ if less than $\$ 10,000 ; 2$ if $\$ 10,000-\$ 24,999 ; 3$ if $25,000-\$ 49,999 ; 4$ if $\$ 50,000-$ $\$ 74,999 ; 5$ if $\$ 75,000$ or more), and race $(R A C E=1$ if white; 0 otherwise.). The $Z$ vector includes dummy variables to control for the 16 different media source combinations in our sample that are comprised from newspapers, radio, TV, the Internet, and Smartphone. ${ }^{10}$

\section{DEMAND ESTIMATES}

The choice data described in Section 3.1 are used to estimate a discrete-choice model of household utility from their local news service. Because 29 respondents do not have geographical identifiers and could not be assigned to their appropriate TV market in Section 5, they are dropped from the final sample of 5,131. Since each of the choice scenarios represent information on preferences from three alternatives, A, B, and actual news service at home, the sample size for econometric estimation is $5,102 \times 8 \times 3=122,448$. Table 2 showed some demographic differences between our final sample and the population. We remedy this possible source of bias in our results by estimating the discrete-choice model by weighted

\footnotetext{
${ }^{10}$ For a robustness check, we specified an alternative set of dummy variables that also controlled for subsets of radio (i.e., satellite and broadcast radio) and TV (i.e., cable, satellite and broadcast TV). Ordered probit estimates of media supply responses, and estimates of the impacts on consumer welfare from a change in market structure, not reported here, are similar to those presented in Tables 10 and 11 below.
} 
maximum likelihood, where the contribution to the log likelihood is the post-stratification weight times the log of the choice probability for the choice occasion.

Table 8 reports weighted maximum likelihood estimates of household utility. Because consumers may have heterogeneous preferences for unmeasured aspects of news service, we estimate utility with an alternative-specific constant to capture differences in tastes between the actual and new (A and B) news services. For purpose of comparison, in model (i) we begin by reporting estimates from a standard conditional logit model with fixed marginal utility parameters. Model (ii) displays estimates from a mixed logit model specification where the four non-price marginal utility parameters are assumed to be independently normally distributed. ${ }^{11}$ Preferences may be correlated, for example, consumers who like more diversity of opinion may also like more information on women and minorities. Accordingly, the mixed logit model (iii) permits correlation between the non-price parameters. Model (iv) reports estimates from a mixed logit model specification with correlated non-price parameters plus COST $\times M E D \_I N C O M E$ and $C O S T \times H I G H \_I N C O M E$. The additional observed consumer characteristics are $M E D \_I N C O M E$ equals one when household income is greater than $\$ 25,000$ and less than \$50,000 and zero otherwise, and HIGH_INCOME equals one when household income is greater than $\$ 50,000$ and zero otherwise. ${ }^{12} 13$

The data fit all model specifications reasonably model well as judged by the sign and statistical significance of most parameter estimates. We focus our discussion on the results from model (iv) because that model permits the marginal disutility of cost to vary by income.

\footnotetext{
${ }^{11}$ All mixed logit models were estimated by simulation using 100 Halton draws. For robustness, we estimated several model specifications using 500 draws and the results are similar.

${ }^{12}$ Low-income households (INCOME < \$25,000) comprise 20.5 percent of the sample, medium-income households $(\$ 25,000 \leq I N C O M E<\$ 50,000)$ comprise 24.6 percent, and high-income households $(\$ 50,000 \leq$ INCOME) comprise 54.9 percent.

${ }^{13} \mathrm{We}$ also estimated a variant of model (iv) that included an additional interaction between an indicator of college education and COST. This additional interaction was not statistically significant at conventional levels and the results, not reported, are similar to those reported in Table 8.
} 
The mean of each of the random marginal utility parameters for DIVERSITY OF OPINION, MULTICULTURALISM and COMMUNITY NEWS are positive and significant at the one percent level, while the mean of the random parameter for ADVERTISING is negative and significant. These estimates imply that the representative consumer's utility increases when there is more diversity in the reporting of news, more information on women and minorities, more information on community news, and less space and/or time devoted to advertising. The fixed parameter for COST is negative and the corresponding parameters for COST $\times M E D \_I N C O M E$ and COST $\times H I G H \_I N C O M E$ are positive. These estimates imply that consumer's utility decreases when the dollar amount paid for their news service increases but that the effect diminishes with increases in household income.

The standard deviations of each of the random marginal utility parameters are significant at the one percent level, indicating that tastes vary in the population. Together, the estimated means and standard deviations of the random parameters provide useful policy information on the percentage of the population that place a positive value on the non-price characteristics of news service. The mean and standard deviation of the parameter estimator for DIVERSITY OF OPINION are 0.443 and 0.801 , respectively. Using the cumulative normal distribution, this implies that about 70 percent of the population prefer more different viewpoints in the reporting of news and 30 percent prefer fewer viewpoints. Similar calculations show that about 80 percent of the population prefer more community news, and more news that reflects the interests of women and minorities is preferred by about one-half of the population. Approximately two-thirds of the population prefer having less advertising.

Although our description of advertising does not measure content, it does measure the amount of space on a newspaper or web page, or the amount of air time devoted to commercial 
advertising on radio or TV. Given this definition and information on public news consumption from the Pew Research Center (2010), we use our demand estimates to shed light on the value of informative vs. non-informative advertising. Given that 58 percent of the U.S. public get their news from the TV, the estimated negative valuations for ADVERTISING likely reflect the consumption of general, all-purpose advertising delivered by traditional media such as radio and TV. In other words, most consumers will indicate their distaste for non-informative advertisements because they do not want to view them or listen to them. In contrast, the estimated positive valuations likely reflect the consumption of more informative, targeted advertisements delivered by new media such as the Internet, Smartphone and Video-onDemand. Here, consumers indicate their preference for advertisements because they are positively informed about something specific to their needs and/or they have some choice in the advertisements they actually view. ${ }^{14}$

In this discussion the coding of the four non-price features in the household utility function is linear, which implies that the marginal utilities are the same when moving from low to medium and from medium to high. We now relax this restriction by replacing each of the four non-price characteristics with a pair of dichotomous variables. For example, MEDIUM DIVERISTY OF OPINION equals one when DIVERISTY OF OPINION equals "medium" and zero otherwise, and HIGH DIVERISTY OF OPINION equals one when DIVERISTY OF OPINION equals "high" and zero otherwise. Here, the estimated parameter on MEDIUM DIVERISTY OF OPINION measures the change in utility from moving from information on news and current affairs in the household's overall news service reflecting only one viewpoint (low diversity) to a few different viewpoints (medium diversity). The estimated parameter on

\footnotetext{
${ }^{14}$ For example, Comcast targets specific customer types through its Video-on-Demand service and then permits the customer to select the advertisements she or he wants to view with their remote control. See http://www.comcastspotlight.com/advertising-solutions/on-demand.
} 
HIGH DIVERISTY OF OPINION measures the change in utility from moving from information on news and current affairs reflecting only one viewpoint to many different viewpoints (high diversity). This approach to estimating non-linear consumer valuations is used for all other non-price characteristics of the local news service.

Mixed logit estimates of the utility model with non-linear preferences are presented in Table 8. Model (v) reported estimates with correlated non-price parameters plus COST $\times M E D \_I N C O M E$ and $C O S T \times H I G H \_I N C O M E$. Focusing on the means of each of the random marginal utility parameters, the results indicate declining marginal utility for the representative consumer with respect to diversity of opinion, multiculturalism and community news. Accompanying WTP calculations by household income are reported in the bottom panel of Table 9. For comparison, WTP calculations from the linear estimates of utility are reported in the top panel. In column three we observe that the representative medium-income consumer is willing to pay $\$ 20.82$ per month for an improvement in diversity of opinion from low to medium, but only another $\$ 6.76$ per month for an additional improvement to high diversity of opinion. Similarly, the representative medium-income household is willing to pay $\$ 24.88$ per month for an initial improvement in information on community news and events from low to medium, but only another $\$ 6.18$ per month for an additional improvement to high. The marginal utility estimates for multiculturalism indicate that households value an improvement in information that reflects the interests of women and minorities from low to medium (i.e., $\mathrm{WTP}=\$ 7.04$ ) more than an improvement from low to high (i.e., WTP $=\$ 4.09$ ). In other words, the representative medium-income household wants more, but not a lot more information reflecting the interests of women and minorities. The marginal utility estimates for advertising indicate a similar pattern to diversity of opinion and community news, albeit in 
reverse. The representative household is willing to pay about $\$ 15.87$ per month for a move from high to medium advertising, but would pay only an additional $\$ 4.70$ per month to move from medium to low advertising. ${ }^{15}$

\section{IMPACT ON WELFARE FROM A CHANGE IN MARKET STRUCTURE}

The demand estimates provide information on the expected societal benefits from increased media diversity and localism. The question of interest now is how do these benefits change with regulatory interventions that shape media market structure? We shed light on this question by estimating the relationships between the number of TV stations in the market and the amount of diversity, localism and advertising supplied within each household's news service. The resulting supply response parameters are then combined with WTP calculations to measure the impact on consumer welfare from a change in media market structure that reduces the number of independent TV voices by one.

\subsection{The supply of news services}

Because unobserved cost and demand factors affect both media market structure and the supply of news service characteristics, the estimated coefficient on VOICES in equation 4 is likely to suffer from omitted variable bias. For example, a market with higher unobserved costs of producing advertising will be less profitable and will attract fewer TV stations. This market may also have more advertising because stations need additional revenue to cover their

\footnotetext{
${ }^{15}$ There are no systematic biases towards a specific alternative within the choice scenario. Consumers chose their actual news service at home 29.1 percent of the time, news service alternative A 34.4 percent of the time, and news service alternative B 36.5 percent of the time. The number of seconds it took respondents to answer each choice occasion remained essentially constant over the eight choice occasions. Because some of our data are from repeated choices, we also need to be concerned with survey fatigue (Savage and Waldman, 2008). For a robustness check, we estimated all model specification's (i) through (v) on the data for the first four choice questions versus the second four questions. The results, not reported, show reasonably similar estimates for the two subsamples of data. There is no systematic pattern that could be taken as evidence of survey fatigue.
} 
higher costs. A standard ordered probit model would bias the estimated relationship between ADVERTISING and VOICES in a negative direction. We account for this endogeneity with a two-stage selection model similar to Mazzeo (2002), Singh and Zhu (2008), and Chen and Savage (2011). In the first stage, we estimate the latent profits of market $m$ with an ordered probit model that predicts the number of independent TV stations in the market. Estimated parameters from the first stage are used to construct a modified error correction term $\left(\hat{\lambda}_{m}\right)$ similar to the inverse Mills ratio in Heckman's (1979) sample selection model. In the second stage, we estimate equation 4 with an ordered probit model of the non-price news characteristic of interest, DIVERISTY OF OPINION, MULTICULTURALISM, COMMUNITY NEWS or ADVERTISING, on VOICES, STATIONS, VOICES $\times S T A T I O N S, Y, Z$ and $\hat{\lambda}$. Since unobserved factors are controlled for by the correction term, the estimated relationship between the supply of news service characteristics and the number of independent TV stations in the market will be consistent.

For the first stage, we specify the representative independent TV station's latent profits to be a function of market size, variable profits per TV household, and fixed costs. ${ }^{16}$ All variables are measured with market-level data from the FCC (2011) and the National Climatic Data Center (2011) and are described in Table A1 of the appendix. The market size variables are the number of TV households (TV_HOUSES) and the projected annual average population growth $\left(P O P \_G R O W T H\right)$. The variables that comprise variable profit are median household income (MEDIUM_INCOME), the number of years of education for the population over 25

\footnotetext{
${ }^{16}$ Because they are not observed, latent profits are approximated by the number of independent TV voices in the market (VOICES). Moreover, because there are independent and non-independent TV voices in the market, this is a simplified description of market structure. An alternative specification could follow Mazzeo (2002) by modeling entry from independent and non-independent TV voices and using the predicted probabilities to form correction terms for both firm types. This is an area of ongoing research for this study.
} 
years of age (EDUC_YEARS), median age of the population (MEDIUM_AGE), percentage of the population that is female (FEMALE_SHARE), percentage of the population that is white (WHITE_SHARE), and population per square mile (DENSITY). Fixed costs are approximated by measures of severe climate that increase the expense of building and maintaining a TV broadcast antenna. They are annual average snowfall $(S N O W)$, annual number of days with the temperature below freezing (FREEZE), and SNOW $\times$ FREEZE.

Ordered probit estimates of the first-stage profits are presented in Table A2 of the appendix. The estimated coefficients on TV_HOUSES and POP_GROWTH indicate that profits are higher in larger markets and that these markets can support more independent TV stations. Household income and the share of female population also have a positive impact on profits, while profits are lower in more densely populated markets. The latter result may be due to the higher cost of marketing and/or the rental price of land in urban and inner-city locations. Profits are higher in markets with more snowfall although the estimated parameter on $S N O W$ is marginally insignificant. This suggests that the fixed cost effect may be offset by the demand effect. Specifically, because their households spend more time indoors and have stronger preferences for TV viewing, markets with more snow earn more revenue and can support more independent TV stations. The estimated coefficients on FREEZE and SNOW $\times F R E E Z E$ are both negative. Snow, sleet and freezing rain can lead to ice buildup and the eventual collapse of the broadcast antennae. Because the fixed costs of constructing and maintaining a more durable antennae are higher in markets with a lot of snow and freezing weather, expected profits are lower.

The estimated cutoff parameters and linear prediction from the first-stage ordered probit model of profits are used to construct the modified correction term: 


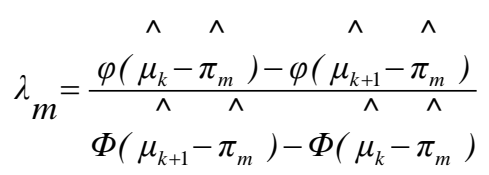

where $\mu_{k}$ are the estimated $k=1,2, \ldots, K$ cutoffs, $K$ is the maximum number of independent TV stations in the sample, $\hat{p}_{m}$ is the linear prediction, $\phi$ is the standard normal density and $\Phi$ is the standard normal distribution. Table 10 presents the second-stage estimates of equation 4 with the modified correction term $\hat{\lambda}_{m}$ included as an additional variable. ${ }^{17}$ The estimated coefficients on the modified correction term are statistically significant for the two diversity characteristics, DIVERISTY OF OPINION and MULTICULTURALISM, and marginally insignificant for the localism characteristic, COMMUNITY NEWS. These results suggests that it is important to account for the potential correlation between the unobserved components of the supply of news service characteristics, and TV station profits.

Focusing on the important variable of interest, we observe that that estimated coefficients on VOICE are positive for all non-price news characteristics, while the estimated coefficients on $V O I C E S \times S T A T I O N S$ are negative. These results suggest that following a decrease in the number of independent TV stations in the market, consumers are more likely to have less diversity of opinion, multiculturalism, community news and advertising in their news service. For example, the sample means of the predicted probabilities of supply presented in the bottom panel of Table 10, show that following the change in market structure, the percentage of households in a low diversity of opinion state will increase by 1.6 , the percentage

\footnotetext{
${ }^{17}$ Because $\lambda_{m}$ is estimated in the first stage, the asymptotic variance of the second-stage estimator is not valid. We report bootstrapped standard errors for supply responses with 100 replications. For robustness, we bootstrapped the standard errors with 500 replications and the results are similar. We also report the original supply response coefficients, which are recovered from the two-stage model using the method described by Imbens and Wooldridge (2007).
} 
of households in a medium state will increase by 3 , and the percentage of households in a high state will decrease by 1.9 . The results with respect to diversity of opinion, multiculturalism and community news are reasonably intuitive. Consolidation of TV stations is associated with the softening of media competition and the provision of less diversity and less local news, which is costly to produce. ${ }^{18}$ The result with respect to advertising is consistent with Crawford's (2007) finding that independent TV stations provide more advertising per program but charge lower prices to advertisers. ${ }^{19}$

5.2 Step three: market structure and consumer welfare

\subsubsection{Algorithm}

We use our demand and supply response estimates from steps one and two to measure the impact on consumer welfare from the change in media market structure. The procedure to calculate the changes to consumer welfare is:

(i) With the existing sample data, use the estimated coefficients from Table 10 to predict each respondent's before probability distribution of low, medium and high values for each of the four non-price news service characteristics. Let $P_{L O}$ be the before probability of a low level of the characteristics, $P_{M O}$ is the before probability of a medium level, and $P_{H O}$ is the before probability of a high level.

(ii) Approximate the change in media market structure by reducing the number of independent TV stations in the sample by one, all other things held constant. Use the

\footnotetext{
${ }^{18}$ By definition, a reduction in the number of independent TV stations means there are fewer viewpoints in the market, and as a result, less diversity of opinion.

${ }^{19}$ Brown and Alexander (2004) find a positive correlation between TV market concentration and the price of advertising per viewer. They argue that when consumer's elasticity of viewing with respect to advertising is weak, a decrease in the fraction of broadcast time devoted to advertising can lead to a decrease in the overall amount of advertising supplied and an increase in the price to advertisers (Cunningham and Alexander, 2004).
} 
estimated coefficients from Table 10 to predict each respondent's after probability distribution of low, medium and high values for each of the four news service characteristics. Let $P_{L l}$ be the after probability of a low level of the characteristic, $P_{M I}$ is the after probability of a medium level, and of the feature; and $P_{H l}$ is the after probability of a high level.

(iii) Use the probabilities in (i) and (ii) to form, for each respondent, $\frac{\Delta P_{L}}{\Delta X}, \frac{\Delta P_{M}}{\Delta X}$ and $\frac{\Delta P_{H}}{\Delta X}$, for each news service characteristics, where $\Delta P_{L}=P_{L 1}-P_{L O}, \Delta P_{M}=P_{M 1}-P_{M 0}$, $\Delta P_{H}=P_{H 1}-P_{H 0}$, and $\triangle X=\Delta V O I C E S=-1$.

(iv) Use the estimates of marginal WTP in the bottom panel of Table 9 and the change in predicted probabilities in (iii) above to evaluate equation 7 for each respondent and for each non-price news service characteristic.

(v) Sort the expected welfare changes in (iv) for each respondent by the number of TV stations, ranging from five to 20 . Calculate the mean expected welfare change per month for all respondents in a market with five stations, six stations, $\ldots$, and 20 stations.

(vi) Use the FCC (2011) data to count the number of population households in a television market with five stations, six stations, $\ldots$, and 20 stations.

(vii) Calculate the aggregate annual change in consumer welfare for each market size by multiplying (v) by 12 by (vi) for each level of the number of television stations, i.e., five stations, six stations, $\ldots$, and 20 stations. 


\subsubsection{Estimates of Consumer Welfare}

Table 11 and Figure 1 present estimates of the impact on consumer welfare from a marginal decrease in the number of independent TV stations for all market sizes ranging from five to 20 TV stations. Columns three through six of Table 11 report average consumer welfare per month and columns seven through twelve report annual aggregate welfare. ${ }^{20}$ The first interesting observation is that the average welfare effects per month depend on market size, with smaller markets having larger effects in absolute terms. The intuition for this finding is clear. The impact from the loss of an independent voice in the market will be more acute when there are fewer competitors to fill the void. As a result, the average consumer in a small market loses $\$ 0.99$ per month, whereas the average consumer in a large market loses $\$ 0.44$ per month. These losses are equivalent to about $\$ 53$ million annually for all small-market households in the U.S. and $\$ 15$ million for all large-market households. ${ }^{21}$ If the change in market structure occurs in all markets, for example, if two of the "big four" networks ABC, CBS, FOX or NBC consolidated, annual aggregate losses nationwide would be about $\$ 830$ million. For comparison, this represents about seven percent of the total operating costs for CBS in $2010 .^{22}$

Given the WTP estimates in Table 9, it is not surprising that the average welfare losses per month from DIVERSITY OF OPINION and COMMUNITY NEWS are greater than MULTICULTURALISM in almost all markets. However, while DIVERSITY OF OPINION continues to have significant negative impacts in both small (-\$0.61) and large (-\$0.38)

\footnotetext{
${ }^{20}$ The reported standard errors are calculated using a bootstrapping method. For example, for row one, we construct the benefit equation 7 for each respondent in markets with five TV stations. We then draw marginal utility values from the multivariate normal distribution implied by the mean and covariance parameters reported in column's eight and nine of Table 7. These values are used to evaluate equation 7 for each respondent and to obtain an estimate of the mean consumer welfare effect per month. We run this simulation 500 times and report the mean and standard error of the sampling distribution for consumer welfare per month.

${ }^{21}$ There are 90,193,905 population households in markets from five to $20 \mathrm{TV}$ stations. Total annual aggregate welfare for small markets is $-\$ 53.36$ million $=(0.050 \times 90,193,905) \times 12 \times-0.99$. Total annual aggregate welfare for large markets is $-\$ 15.51$ million $=(0.032 \times 90,193,905) \times 12 \times-0.44$.

${ }^{22}$ See CBS Corporation income statements at http://ycharts.com/financials/CBS/income_statement/annual.
} 
markets, the effect for COMMUNITY NEWS quickly dissipates from $-\$ 0.45$ to $-\$ 0.09$ as the number of stations in the market increases. MULTICULTURALISM follows a similar trend to DIVERSITY OF OPINION, losing about 40 percent of its negative impact from small (-\$0.23) to large (-\$0.14) markets. ADVERTISING also follows a similar trend to DIVERSITY OF OPINION and MULTICULTURALISM losing about 40 percent of its positive impact from small (\$0.30) to large $(\$ 0.17)$ markets.

A final interesting observation is the potential tradeoff between the amount of diversity and localism in news service, and the amount of space and time devoted to advertising. Consumers lose from the consolidation of two independent TV stations because there is less diversity of opinion, less coverage of multiculturalism issues and less community news, but they gain because there is less space and time devoted to advertising. ${ }^{23}$ Specifically, columns three through six of Table 11 show that, on average, about 24 percent of the annual monthly losses to consumers from less diversity and localism in each market are offset by less exposure to advertising. This illustrates an important feature of the news service experience in our data; the first-order effects from consolidation are, potentially, not all bad for consumers. Nevertheless, consumers and policy makers should be concerned about the impacts from a “virtual merger" where TV stations combine their news operations with joint operating and marketing agreements without actually merging. Since a virtual merger is likely to result in less diversity and localism but not less advertising, the welfare reductions in Table 11 would be

\footnotetext{
${ }^{23}$ The reduction in advertising does not mean that that the two merged firms will be worth less. Profits are expected to increase as a result of higher advertising rates and/or cost efficiencies in the production of news programming.
} 
even more pronounced. For example, column twelve shows that if the virtual merger occurred in all markets, annual aggregate losses nationwide would be about $\$ 1.1$ billion. $^{24}$

\section{CONCLUSIONS}

This study examined market structure and media diversity. A differentiated product model was used to estimate consumer demand for their local news service, described by the offerings from newspapers, radio, TV, the Internet, and Smartphone. The model captures both private and public good aspects of news service by including the amount of advertising in the household's full cost of consumption, and by characterizing service in terms of diversity of opinion in the reporting of information, coverage of multiculturalism issues, and the amount of information on community news and events. The empirical results show that the representative consumer values diversity in the reporting of news, more information on women and minorities, and more information on community news. Many consumers, however, have a distaste for advertising, which likely reflects their consumption of general, all-purpose advertising from traditional media.

The demand estimates are used to calculate the impact on consumer welfare from a marginal decrease in the number of independent TV stations that lowers the amount of diversity, localism and advertising in the market. The prediction of non-price effects is appropriate for media markets, where some households make no direct payment for consumption, and appears to be novel in the simulated merger literature. Our results show that

\footnotetext{
${ }^{24}$ The FCC use several measures of market structure when discussing ownership rules. For robustness, we examined how sensitive our results are to an alternative specification of the media supply response equation 4 that controls for the number of daily newspapers in the market (NEWSPAPERS) and the number of radio stations (RADIO STATIONS). The estimates of the two-stage ordered probit model of supply, and the estimates of the impacts on consumer welfare from a change in market structure, not reported here, are similar to those presented in Tables 10 and 11.
} 
consumer welfare decreases following the change in media market structure, and that the losses are smaller in large markets. For example, small-market consumers lose $\$ 53$ million annually while large-market consumers lose $\$ 15$ million. If the change in market structure occurs in all markets, total losses would be about $\$ 830$ million.

We make no claims as to whether media ownership rules should be relaxed or tightened. We note that the estimated total losses of $\$ 830$ million approximates the extreme case of consolidation between two major national media players and, as such, is an upperbound calculation. The large consumer losses in small TV markets relative to large markets is potentially important. The tradeoff between diversity and localism, and advertising, is also interesting because it highlights an additional benefit for consideration during the analysis of a media market merger. It also provides a new angle from which to assess the efficacy of media ownership rules. 


\section{APPENDIX}

\section{Table A1. Television Market Profit Variables}

\begin{tabular}{|c|c|c|}
\hline Variable & Description and data source & $\begin{array}{l}\text { Mean } \\
\text { (s.d.) }\end{array}$ \\
\hline TV_HOUSES & $\begin{array}{l}\text { Number of households (in 1000's) in the market that own a TV set at } 2009 . \\
\text { Source: FCC (2011). }\end{array}$ & $\begin{array}{r}547.0 \\
(835.7)\end{array}$ \\
\hline POP_GROWTH & $\begin{array}{l}\text { Projected average annual population growth in the market. Source: FCC } \\
\text { (2011). }\end{array}$ & $\begin{array}{r}0.007 \\
(0.012)\end{array}$ \\
\hline MEDIAN_INCOME & $\begin{array}{l}\text { Median household income (in } \$ 1,000 \text { 's) in the market at 2008. Source: FCC } \\
\text { (2011). }\end{array}$ & $\begin{array}{r}46.42 \\
(8.451)\end{array}$ \\
\hline EDUC_YEARS & $\begin{array}{l}\text { Mean number of years of schooling for the population over } 25 \text { years of age in } \\
\text { the market (five-year estimate 2005-2009). Source: FCC (2011). }\end{array}$ & $\begin{array}{c}13.29 \\
(0.647)\end{array}$ \\
\hline MEDIUM_AGE & $\begin{array}{l}\text { Median years of age of the population in the market (five-year estimate 2005- } \\
\text { 2009). Source: FCC (2011). }\end{array}$ & $\begin{array}{c}37.07 \\
(3.122)\end{array}$ \\
\hline FEMALE_SHARE & Fraction of the market population that is female at 2009. Source: FCC (2011) & $\begin{array}{r}0.497 \\
(0.028)\end{array}$ \\
\hline WHITE_SHARE & Fraction of the market population that is white at 2009. Source: FCC (2011). & $\begin{array}{r}0.800 \\
(0.130)\end{array}$ \\
\hline DENSITY & $\begin{array}{l}\text { Total population (in 1000's) per square mile in the market (five-year estimate } \\
\text { 2005-2009). Source: FCC (2011). }\end{array}$ & $\begin{array}{c}0.152 \\
(0.210)\end{array}$ \\
\hline SNOW & $\begin{array}{l}\text { Annual average total inches of snowfall, including ice pellets and sleet, in the } \\
\text { market or closest weather recording station to the market (30-year estimate } \\
\text { 1971-2000). Source: National Climatic Data Center (2011). }\end{array}$ & $\begin{array}{c}24.75 \\
(27.62)\end{array}$ \\
\hline FREEZE & $\begin{array}{l}\text { Annual average number of days with minimum temperature of } 32 \text { degrees } \\
\text { Fahrenheit or less in the market or closest weather recording station to the } \\
\text { market (30-year estimate 1971-2000). Source: National Climatic Data Center } \\
\text { (2011). }\end{array}$ & $\begin{array}{c}91.88 \\
(57.35)\end{array}$ \\
\hline
\end{tabular}

NOTES. s.d. is standard deviation. 
Table A2. First-Stage Ordered Probit Estimates of TV Market Profits

\begin{tabular}{lc}
\hline & Estimated Coefficients \\
\hline TV_HOUSES & $0.002^{* * *}$ \\
& $(0.0005)$ \\
POP_GROWTH & $15.68^{* *}$ \\
& $(7.436)$ \\
Log MEDIAN_INCOME & $1.713^{*}$ \\
EDUC_YEARS & $(0.879)$ \\
& -0.006 \\
MEDIAN_AGE & $(0.190)$ \\
& -0.021 \\
FEMALE_SHARE & $(-0.032)$ \\
& $9.388^{* * *}$ \\
WHITE_SHARE & $(2.656)$ \\
& -0.242 \\
DENSITY & $(0.829)$ \\
& $-2.710^{* * *}$ \\
SNOW & $(0.763)$ \\
& 0.015 \\
FREEZE & $(0.011)$ \\
SNOW $\times$ FREEZE & $-0.007^{* * *}$ \\
Likelihood & $(0.002)$ \\
in pares. Estimated by maximum likelihood. Robust standard errors & -0.00003 \\
parameters are not reported. Number of observations is 210. \\
\end{tabular}




\section{REFERENCES}

Berry, S., and Waldfogel, J. 2001. "Do Mergers Increase Product Variety? Evidence from

Radio Broadcasting." Quarterly Journal of Economics, 116(3), 1009-1025.

Brown, K., and Alexander, P. 2004. "Market Structure, Viewer Welfare, and Advertising Rates in Local Broadcast Markets." Economic Letters, 86(3), 331-337.

Brownstone, D., and K. Train. 1999. "Forecasting New Product Penetration with Flexible

Substitution Patterns." Journal of Econometrics, 89(1), 109-129.

Chen, Y., and Savage, S. 2011. "The Effects of Competition on the Price for Cable Modem

Internet Access." The Review of Economics and Statistics, 93(1), 201-217.

Crawford, G. 2007. "Television Station Ownership Structure and the Quantity and Quality of

TV Programming,” FCC Media Ownership Study \#3, Washington, D.C., FCC.

Cunningham, B., and Alexander, P. 2004. "A Theory of Broadcast Media Concentration and

Commercial Advertising." Journal of Public Economic Theory, 6(4), 557-575.

Domberger, S., and Sherr, A. 1989. "The Impact of Competition on Pricing and Quality of

Legal Services." International Review of Law and Economics, 9, 41-56.

Economides, N., Seim, K., and Viard, B. 2008. "Quantifying the Benefits of Entry into Local

Phone Service." RAND Journal of Economics, 39(3), 699-730.

FCC. 2011. Government Furnished Information on Media Market Structure. February 17,

Media Bureau, FCC, Washington, D.C.

Gentzkow, M. 2007. "Valuing New Goods in a Model with Complementary Online

Newspapers." American Economic Review, 97(3), 713-744.

Gentzkow, M., and Shapiro, J. 2010. "What Drives Media Slant? Evidence from U.S. Daily

Newspapers." Econometrica, 78(1), 35-71.

Goolsbee, A. and Petrin, A. 2004. "The Consumer Gains from Direct Broadcast Satellites and

the Competition with Cable TV." Econometrica, 72(2), 351-81.

Heckman, J. 1979. "Sample Selection Bias as a Specification Error.” Econometrica, 47(1), $153-61$.

Huber J., and Zwerina, K. 1996. "The Importance of Utility Balance in Efficient Choice

Designs. Journal of Marketing Research, 33, 307-317.

Imbens, G., and Wooldridge, J. 2007. "Control Function and Related Methods." Lecture Notes 6 for What's New in Econometrics? NBER.

Ivaldi, M., and Verboven, F. 2005. "Quantifying the Effects from Horizontal Mergers in

European Competition Policy." International Journal of Industrial Organization, 23(9/10), 669-691.

Knowledge Networks Inc. 2010. KnowledgePanel®Demographic Profile January 2010.

Government and Academic Research, Knowledge Networks.

Matsa, D. 2011. "Competition and Product Quality in the Supermarket Industry." Quarterly Journal of Economics, 126(3), 1539-1591.

Mazzeo, M. 2002. "Competitive Outcomes in Product-Differentiated Oligopoly." The Review of Economics and Statistics, 84(4), 716-728.

Mazzeo, M. 2003. "Competition and Service Quality in the US Airline Industry." Review of Industrial Organization, 22(4), 275-296.

Milyo, J. 2007. "The Effects of Cross-Ownership on the Local Content and Political Slant of Local Television News.” FCC Media Ownership Study \#6, Washington, D.C., FCC. 
National Climatic Data Center. 2011. Climate Data Online. Washington, D.C.: U.S.

Department of Commerce, http://www.ncdc.noaa.gov/cdo-web/.

Nevo, A. 2000. "Mergers With Differentiated Products: The Case of the Ready to Eat Cereal Industry." Rand Journal of Economics, 31(3), 395-421.

Nielson Company. 2010. "iPhone, Android Show Growth," http://www.marketingcharts.com/wp/wp-content/uploads/2010/08/nielsen-smartphonepenetration-q2-10-august-2010.JPG.

Olivares, M., and Cachon, G. 2009. "Competing Retailers and Inventory: An Empirical Investigation of General Motors' Dealerships in Isolated U.S. Markets.” Management Science, 55(9), 1586-1604.

Pew Research Center. 2010. "Ideological News Sources: Who Watches and Why?" Pew Research Centre Publication, Accessed on August 14, 2012 at http://www.peoplepress.org/files/legacy-pdf/652.pdf.

Pinkse, J., and Slade, M. 20004. "Mergers, Brand Competition and the Price of a Pint." European Economic Review, 48(3), 617-643.

Revelt, D., and K. Train. 1998. "Mixed Logit with Repeated Choices: Households' Choices of Appliance Efficiency Level." The Review of Economics and Statistics, 80(4), 647-657.

Savage, S., and Waldman, D. 2008. "Learning and Fatigue During Choice Experiments: A Comparison of Online and Mail Survey Modes," Journal of Applied Econometrics 23(3), 351-371.

Savage, S., and Waldman, D. 2011. "Consumer Valuation of Media as a Function of Local Market Structure.” FCC Media Ownership Study \#2, Washington, D.C.: FCC.

Siegelman, P., and Waldfogel, J. 2001. "Race and Radio: Preference Externalities, Minority Ownership, and the Provision of Programming to Minorities." In Baye, M., and Nelson, J., eds., Advances in Applied Microeconomics, Vol. 10: Advertising and Differentiated Products, Elsevier, Amsterdam.

Singh, V., and Zhu, T. 2008. "Pricing and Market Concentration in Oligopoly Markets." Marketing Science, 27(6), 1020-1035.

United States Census Bureau. 2009. American Factfinder. Washington, D.C.: United States Census Bureau.

United States Census Bureau. 2011. Statistical Abstract of the United States: 2012 (131st Edition). Washington, D.C.: , 2011; United States Census Bureau.

Yan, M., and Napoli, P. 2006. "Market Competition, Station Ownership, and Local Public Affairs Programming on Broadcast Television," Journal of Communications, 56(1), 795-812.

Zavoina, R. and W. McKelvey. 1975. "A Statistical Model for the Analysis of Ordinal Level Dependent Variables." Journal of Mathematical Sociology, 103-120. 


\section{Table 1. Summary of News Service Characteristics}

\begin{tabular}{ll}
\hline Characteristic & Levels \\
\hline COST & The total of monthly subscriptions to all of the household's media sources, \\
plus any contributions to public radio or public TV stations (ranging from $\$ 0$ \\
to $\$ 250$ per month). \\
The extent to which the information on news and current affairs in the \\
household's overall media environment reflects different viewpoints. \\
Low: only one viewpoint. \\
Medium: a few different viewpoints. \\
High: many different viewpoints. \\
The amount of information on community news and events in the \\
household's overall media environment. \\
Low: very little or no information on community news and events. \\
Medium: some information on community news and events. \\
High: much information on community news and events. \\
The amount of information on news and current affairs in the household's \\
overall media environment that reflects the interests of women and \\
minorities. \\
Low: very little or no information reflecting the interests of women and \\
minorities. \\
Medium: some information reflecting the interests of women and minorities. \\
High: much information reflecting the interests of women and minorities. \\
The amount of space and/or time devoted to advertising in the household's \\
overall media environment. \\
Low: barely noticeable. \\
Medium: noticeable but not annoying. \\
High: annoying.
\end{tabular}

NOTES. The upper limit of $\$ 250$ per month for COST is the total cost for a media environment with a seven-day subscription to a premium newspaper, such as the New York Times or San Francisco Chronicle (\$25), a "All of XM" subscription to satellite radio (\$20), a premier subscription to cable or satellite television $(\$ 110)$, a subscription to very-fast Internet service (\$45), an unlimited data subscription for a Smartphone (\$30), and \$10 monthly memberships to both NPR and PBS. Detailed descriptions of the characteristics as they appeared in the survey questionnaire are available in Savage and Waldman (2011). 
Table 2. Demographic Distributions (\%)

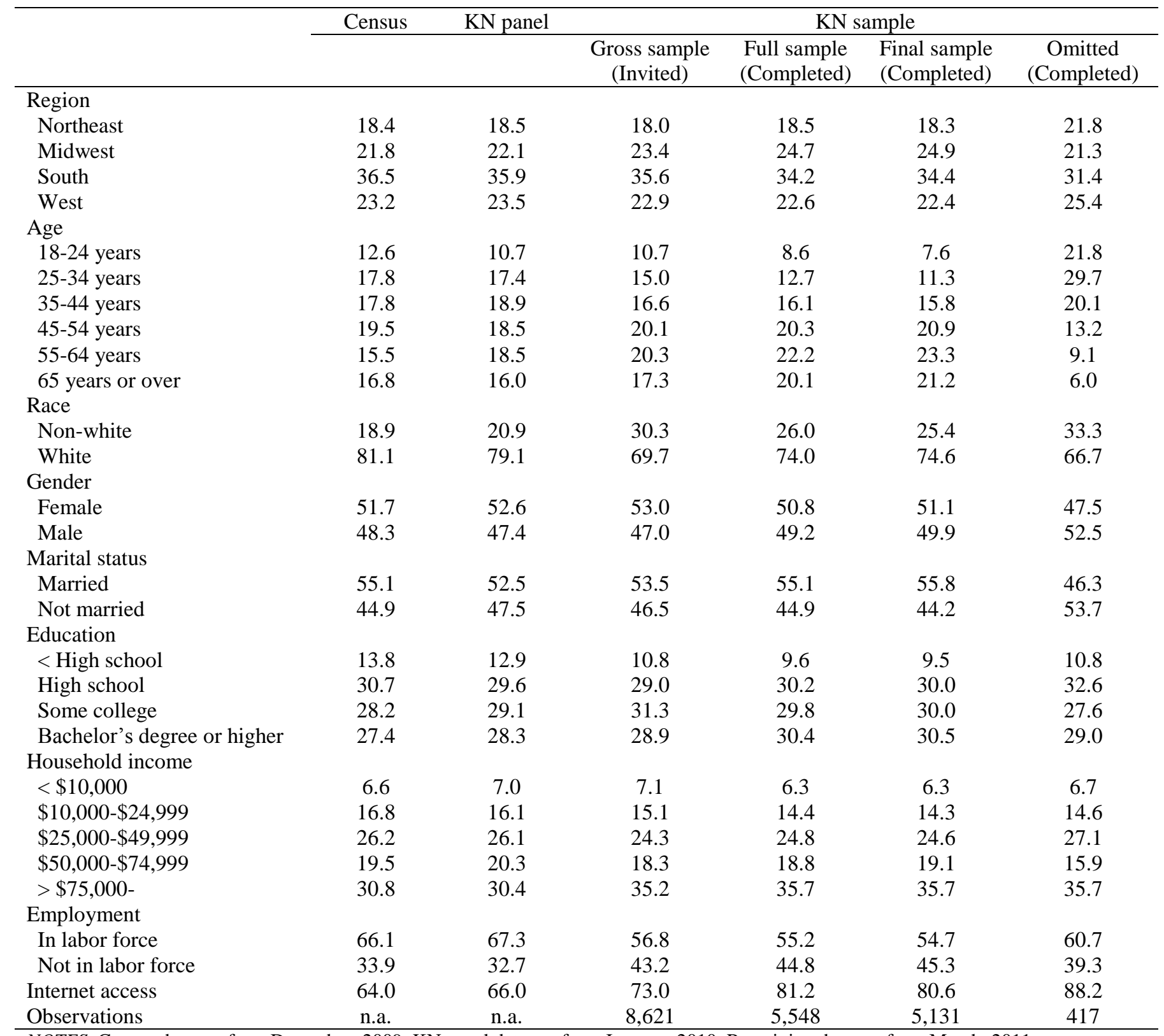

NOTES. Census data are from December, 2009. KN panel data are from January, 2010. Remaining data are from March, 2011.

SOURCE. United States Census Bureau (2009); Knowledge Networks, Inc. (2010). 
Table 3. Summary Statistics for Media Sources

\begin{tabular}{lcccccc}
\hline Media source & Obs. & $\begin{array}{c}\text { Sample } \\
\text { share (\%) }\end{array}$ & Mean & s.d. & Min & Max \\
\hline Newspaper & 2,342 & 45.6 & 1.015 & 1.766 & 0 & 24 \\
Radio & 4,154 & 81.2 & 1.423 & 1.873 & 0 & 24 \\
Satellite radio & 558 & 10.9 & 1.522 & 2.221 & 0 & 24 \\
Television & 4,856 & 94.6 & 1.953 & 2.172 & 0 & 24 \\
Cable television & 2,736 & 53.4 & 1.976 & 2.210 & 0 & 24 \\
Satellite television & 1,381 & 27.0 & 2.071 & 2.197 & 0 & 24 \\
Own Internet & 4,135 & 80.6 & 1.074 & 1.659 & 0 & 24 \\
Smartphone & 1,270 & 24.8 & 0.580 & 1.344 & 0 & 24 \\
\hline
\end{tabular}

NOTES. Obs. is the number of observations. Sample share is the percentage of the sample that uses the media source. s.d. is standard deviation. Min is minimum value. Max is maximum value. Own Internet is home Internet service not provided by KN. 
Table 4. Summary Statistics for News Service Characteristics

\begin{tabular}{lccccc}
\hline Feature & Obs. & Mean & s.d. & Min & Max \\
\hline DIVERSITY OF OPINION & 5,131 & 2.09 & 0.655 & 1 & 3 \\
COMMUNITY NEWS & 5,131 & 1.99 & 0.711 & 1 & 3 \\
MULTICULTURALISM & 5,131 & 1.83 & 0.705 & 1 & 3 \\
ADVERTISING & 5,131 & 2.29 & 0.682 & 1 & 3 \\
COST (\$ per month) & 5,131 & 111.2 & 76.03 & 0 & 447 \\
CONTRIBUTION (\$ annual) & 535 & 111.5 & 161.5 & 0.25 & 1,500 \\
BUNDLE & 3,688 & 0.576 & 0.494 & 0 & 1 \\
\hline
\end{tabular}

NOTES. 1 = "low", 2 = "medium" and 3 = "high" for DIVERSITY OF OPINION, COMMUNITY NEWS, MULTICULTURALISM, and ADVERTISING. CONTRIBUTION is value of contributions to public radio and public TV stations during the past 12 months. BUNDLE $=1$ when subscription television service is bundled with Internet service and/or other telephone services. Obs. Is the number of observations. s.d. is standard deviation. Min is minimum value. Max is maximum value. 
Table 5. External Validation of Diversity and Localism

\begin{tabular}{lcc}
\hline & \multicolumn{2}{c}{$\begin{array}{c}\text { DIVERSITY O } \\
\text { OPINION }\end{array}$} \\
\cline { 2 - 3 } External measures & Radio & TV \\
\hline Number of stations that & -0.0121 & \\
radio multicast & $(0.0199)$ & \\
Number of stations that & & $0.0425^{* *}$ \\
TV multicast & & $(0.0137)$ \\
& & \\
Number of non- & & $0.0430^{* * *}$ \\
commercial stations & $(0.0020)$ & $(0.0106)$ \\
& & \\
Number of different & $0.0036^{* * *}$ & \\
radio formats & $(0.0008)$ &
\end{tabular}

Gentzkow-Shapiro Slant

$-3.959^{* * *}$

Measure

(1.040)

Number of stations with

$0.0347^{* *} \quad 0.0364^{*}$

female ownership

$(0.0123) \quad(0.0184)$

Number of stations with

$0.0034^{*} \quad 0.0254^{* * *}$

minority ownership

(0.0013)

(0.0064)

Number of commercial

$-0.0004$

radio stations owned by

(0.0005)

parent entities

Number of commercial

$-0.0018$

TV stations owned by

parent entities

NOTES. Ordered probit model of DIVERISTY OF OPINION, MULTICULTURALISM or COMMUNITY NEWS, on individual external measures is estimated by weighted maximum likelihood. Robust standard errors in parentheses. ${ }^{* * *}$ denotes significant at the one percent level. ${ }^{* * *}$ denotes significant at the five percent level. "denotes significant at the ten percent level. External measures are from the FCC (2011). Multicast is the number of stations in the market that broadcast multiple program streams. The measure of slant is from Gentzkow and Shapiro (2010) and is the average absolute value of the slant toward Republican or Democrat of local newspapers. Estimated cutoff parameters are not reported. Number of observations is 5,102, with the exception of Column 3, where observations total 4,616. 


\section{Table 6. Media Market Structure}

\begin{tabular}{ll}
\hline Variable & \multicolumn{1}{c}{ Description } \\
\hline HOUSEHOLDS & Number of households in the market. \\
NEWSPAPERS & Number of daily newspapers with a city of publication located in a county in the market. \\
RADIO STATIONS & Number of radio stations in the market. \\
STATIONS & Number of full-power TV stations in the market. \\
MEDIA OUTLETS & NEWSPAPERS plus RADIO STATIONS plus STATIONS. \\
NEWSPAPER VOICES & Number of parent entities owning a daily newspaper in the market. \\
RADIO VOICES & Number of independent radio voices in the market. \\
VOICES & Number of independent TV voices in the market. \\
MEDIA VOICES & NEWSPAPER VOICES plus RADIO VOICES plus VOICES. \\
TV-NEWSPAPER VOICES & Number of independent newspaper and TV voices in the market. \\
TV-RADIO VOICES & Number of independent radio and TV voices in the market. \\
\hline
\end{tabular}

SOURCE. FCC (2011). 
Table 7. Summary Statistics for Media Market Structure

\begin{tabular}{|c|c|c|c|c|c|c|c|}
\hline Variable & Markets & Mean & s.d. & Min & 25 th & 75th & Max \\
\hline \multicolumn{8}{|l|}{$\underline{\text { All markets }}$} \\
\hline HOUSEHOLDS & 203 & $1,670,158$ & $1,842,396$ & 4,145 & 447,396 & $2,228,143$ & $7,444,659$ \\
\hline SMALL MARKETS & 203 & 0.084 & 0.278 & 0 & n.a. & n.a. & 1 \\
\hline MEDIA OUTLETS & 203 & 138.7 & 71.25 & 4 & 80 & 182 & 291 \\
\hline MEDIA VOICES & 203 & 73.11 & 35.97 & 3 & 44 & 97 & 152 \\
\hline NEWSPAPERS & 203 & 12.76 & 8.206 & 0 & 6 & 19 & 32 \\
\hline RADIO STATIONS & 203 & 113.2 & 59.41 & 3 & 64 & 157 & 241 \\
\hline STATIONS & 203 & 12.74 & 5.879 & 1 & 8 & 17 & 27 \\
\hline NEWSPAPER VOICES & 203 & 7.634 & 4.076 & 0 & 4 & 10 & 19 \\
\hline RADIO VOICES & 203 & 55.12 & 28.75 & 2 & 31 & 73 & 119 \\
\hline VOICES & 203 & 10.36 & 4.626 & 1 & 7 & 13 & 22 \\
\hline TV-NEWSPAPER VOICES & 203 & 11.91 & 4.758 & 1 & 8 & 15 & 24 \\
\hline TV-RADIO VOICES & 203 & 63.06 & 30.95 & 2 & 38 & 85 & 129 \\
\hline
\end{tabular}

$\underline{\text { Small markets (five or fewer TV stations) }}$

$\begin{array}{lccccccc}\text { HOUSEHOLDS } & 68 & 195,814 & 98,806 & 4,145 & 116,273 & 264,844 & 395,620 \\ \text { MEDIA OUTLETS } & 68 & 46.97 & 15.90 & 4 & 37 & 57 & 86 \\ \text { MEDIA VOICES } & 68 & 26.36 & 8.695 & 3 & 20 & 34 & 41 \\ \text { NEWSPAPERS } & 68 & 4.160 & 2.347 & 0 & 2 & 6 & 11 \\ \text { RADIO STATIONS } & 68 & 38.60 & 13.85 & 3 & 30 & 48 & 75 \\ \text { STATIONS } & 68 & 4.211 & 1.060 & 1 & 4 & 5 & 5 \\ \text { NEWSPAPER VOICES } & 68 & 3.308 & 1.900 & 0 & 2 & 4 & 8 \\ \text { RADIO VOICES } & 68 & 19.00 & 6.608 & 2 & 14 & 25 & 31 \\ \text { VOICES } & 68 & 4.046 & 1.097 & 1 & 3 & 5 & 5 \\ \text { TV-NEWSPAPER VOICES } & 68 & 5.734 & 1.302 & 1 & 5 & 7 & 8 \\ \text { TV-RADIO VOICES } & 68 & 22.54 & 7.316 & 2 & 17 & 28 & 35\end{array}$

NOTES. Markets is the number of television markets. s.d. is standard deviation. Min is minimum value. Max is maximum value. $25^{\text {th }}$ is $25^{\text {th }}$ percentile. $75^{\text {th }}$ is $75^{\text {th }}$ percentile. n.a. is not applicable. 
Table 8. Mixed Logit Estimates of the Demand for Local News Service

\begin{tabular}{|c|c|c|c|c|c|c|c|c|c|}
\hline & \multirow{2}{*}{$\frac{\text { Model (i) }}{\text { Mean }}$} & \multicolumn{2}{|c|}{ Model (ii) } & \multicolumn{2}{|c|}{ Model (iii) } & \multicolumn{2}{|c|}{ Model (iv) } & \multicolumn{2}{|c|}{ Model (v) } \\
\hline & & Mean & s.d. & Mean & s.d. & Mean & s.d. & Mean & s.d. \\
\hline COST & $\begin{array}{l}-0.020^{* * * *} \\
(0.0002)\end{array}$ & $\begin{array}{l}-0.028^{* * * *} \\
(0.0003)\end{array}$ & & $\begin{array}{l}-0.028^{\text {**** }} \\
(0.0003)\end{array}$ & & $\begin{array}{l}-0.037^{\text {*3* }} \\
(0.001)\end{array}$ & & $\begin{array}{l}-0.042^{* * *} \\
(0.001)\end{array}$ & \\
\hline COST $\times M E D \_I N C O M E$ & & & & & & $\begin{array}{l}0.004^{* * *} \\
(0.001)\end{array}$ & & $\begin{array}{l}0.005^{* * *} \\
(0.001)\end{array}$ & \\
\hline COST $\times H I G H \_I N C O M E$ & & & & & & $\begin{array}{l}0.011^{* * *} \\
(0.001)\end{array}$ & & $\begin{array}{l}0.013^{\text {*** }} \\
(0.001)\end{array}$ & \\
\hline DIVERSITY OF OPINION & $\begin{array}{l}0.383^{* * *} \\
(0.009)\end{array}$ & $\begin{array}{l}0.433^{* * *} \\
(0.016)\end{array}$ & $\begin{array}{l}0.810^{\text {*** }} \\
(0.019)\end{array}$ & $\begin{array}{l}0.448^{* * *} \\
(0.016)\end{array}$ & $\begin{array}{l}0.805^{* * *} \\
(0.019)\end{array}$ & $\begin{array}{l}0.443^{* * *} \\
(0.016)\end{array}$ & $\begin{array}{l}0.801^{\text {*** }} \\
(0.019)\end{array}$ & & \\
\hline COMMUNITY NEWS & $\begin{array}{l}0.461^{* * *} \\
(0.009)\end{array}$ & $\begin{array}{l}0.433^{* * *} \\
(0.014)\end{array}$ & $\begin{array}{l}0.649^{* * *} \\
(0.018)\end{array}$ & $\begin{array}{l}0.450^{* * *} \\
(0.014)\end{array}$ & $\begin{array}{l}0.591^{* * *} \\
(0.019)\end{array}$ & $\begin{array}{l}0.449^{* * *} \\
(0.014)\end{array}$ & $\begin{array}{l}0.590^{* * *} \\
(0.019)\end{array}$ & & \\
\hline MULTICULTURALISM- & $\begin{array}{c}0.012 \\
(0.009)\end{array}$ & $\begin{array}{c}0.015 \\
(0.015)\end{array}$ & $\begin{array}{l}0.685^{* * *} \\
(0.019)\end{array}$ & $\begin{array}{l}0.041^{* * *} \\
(0.015)\end{array}$ & $\begin{array}{l}0.599^{* * *} \\
(0.021)\end{array}$ & $\begin{array}{l}0.041^{* * *} \\
(0.015)\end{array}$ & $\begin{array}{l}0.604^{* * *} \\
(0.021)\end{array}$ & & \\
\hline ADVERTISING & $\begin{array}{l}-0.357^{* * *} \\
(0.010)\end{array}$ & $\begin{array}{l}-0.227^{* * *} \\
(0.016)\end{array}$ & $\begin{array}{l}0.695^{* * *} \\
(0.019)\end{array}$ & $\begin{array}{l}-0.229^{\text {*** }} \\
(0.016)\end{array}$ & $\begin{array}{l}0.692^{* * *} \\
(0.020)\end{array}$ & $\begin{array}{l}-0.244^{* * *} \\
(0.016)\end{array}$ & $\begin{array}{l}0.681^{* * *} \\
(0.020)\end{array}$ & & \\
\hline $\begin{array}{l}\text { MEDIUM DIVERSITY OF OPINION } \\
\text { HIGH DIVERSITY OF OPINION }\end{array}$ & & & & & & & & $\begin{array}{c}0.748^{\text {*** }} \\
(0.032)^{\text {*** }} \\
0.991^{\text {*** }} \\
(0.037)\end{array}$ & $\begin{array}{c}1.295^{\text {*** }} \\
(0.043)^{\text {**** }} \\
1.076^{\text {*** }} \\
(0.043)\end{array}$ \\
\hline MEDIUM COMMUNITY NEWS & & & & & & & & $\begin{array}{l}0.894^{* * *} \\
(0.033)\end{array}$ & $\begin{array}{l}1.197^{* * *} \\
(0.045)\end{array}$ \\
\hline HIGH COMMUNITY NEWS & & & & & & & & $\begin{array}{l}1.116^{* * *} \\
(0.034)\end{array}$ & $\begin{array}{l}0.510^{* * *} \\
(0.072)\end{array}$ \\
\hline MEDIUM MULTICULTURALISM & & & & & & & & $\begin{array}{l}0.253^{* * *} \\
(0.027)\end{array}$ & $\begin{array}{l}0.473^{\text {*** }} \\
(0.075)\end{array}$ \\
\hline HIGH MULTICULTURALISM & & & & & & & & $\begin{array}{l}0.147^{* * * *} \\
(0.032)\end{array}$ & $\begin{array}{l}0.159^{\text {**** }} \\
(0.062)\end{array}$ \\
\hline MEDIUM ADVERTISING & & & & & & & & $\begin{array}{l}-0.169^{* * *} \\
(0.023)\end{array}$ & $\begin{array}{l}-0.029^{* * * *} \\
(0.049)\end{array}$ \\
\hline
\end{tabular}


$0.888^{* * *}$

$(0.021)$

$-59,453$

$-32,714$

$-32,477$

NOTES. Estimated by simulated weighted maximum likelihood. (i

$0.888^{* * *}$

(0.039)

(0.081) denotes significant at the one percent level. ${ }^{* *}$ denotes significant at the five percent level. ${ }^{*}$ denotes significant at the ten percent level. Number of observations is 122,448 . 
Table 9. Willingness-to-Pay by Household Income

\begin{tabular}{lrrr}
\hline & $\begin{array}{r}\text { Low income }< \\
\$ 25,000\end{array}$ & $\begin{array}{r}\$ 25,000 \leq \\
\text { Medium income } \\
<\$ 50,000\end{array}$ & $\begin{array}{r}\$ 50,000 \leq \\
\text { High income }\end{array}$ \\
\hline Linear preferences & & & \\
DIVERSITY OF OPINION & $\$ 12.14$ & $\$ 13.61$ & $\$ 17.65$ \\
COMMUNITY NEWS & $\$ 12.30$ & $\$ 13.79$ & $\$ 17.89$ \\
MULTICULTURALISM & $\$ 1.12$ & $\$ 1.25$ & $\$ 1.62$ \\
ADVERTISING & $\$(6.68)$ & $\$(7.49)$ & $\$(9.72)$ \\
Non-linear preferences & & & \\
MEDIUM DIVERSITY OF OPINION & $\$ 18.16$ & $\$ 20.82$ & $\$ 26.34$ \\
HIGH DIVERSITY OF OPINION & $\$ 24.05$ & $\$ 27.58$ & $\$ 34.89$ \\
MEDIUM COMMUNITY NEWS & $\$ 21.70$ & $\$ 24.88$ & $\$ 31.48$ \\
HIGH COMMUNITY NEWS & $\$ 27.09$ & $\$ 31.06$ & $\$ 39.30$ \\
MEDIUM MULTICULTURALISM & $\$ 6.14$ & $\$ 7.04$ & $\$ 8.91$ \\
HIGH MULTICULTURALISM & $\$ 3.57$ & $\$ 4.09$ & $\$ 5.18$ \\
MEDIUM ADVERTISING & $\$(4.10)$ & $\$(4.70)$ & $\$(5.95)$ \\
HIGH ADVERTISING & $\$(17.94)$ & $\$(20.57)$ & $\$(26.02)$ \\
\hline NOTES. W & &
\end{tabular}

NOTES. Willingness-to-pay is calculated using the mean of each of the random marginal utility parameters and the marginal disutility of COST. The marginal disutility of COST varies by household income and is $\beta_{1}+\beta_{M} M E D \_I N C O M E+\beta_{H} H I G H \_I N C O M E$, where $M E D \_I N C O M E$ equals one when household income is greater than $\$ 25,000$ and less than $\$ 50,000$ and zero otherwise, and HIGH_INCOME equals one when household income is greater than $\$ 50,000$ and zero otherwise. Linear calculations use utility estimates from model (iv) in Table 7. Non-linear calculations use utility estimates from model (v) in Table 7. The parentheses on MEDIUM DVERTISING indicate WTP to move from a medium to a low level of advertising. The parentheses on HIGH ADVERTISING indicate WTP to move from a high to a low level of advertising. 
Table 10. Second-Stage Ordered Probit Estimates of Media Supply Responses

\begin{tabular}{|c|c|c|c|c|}
\hline & $\begin{array}{c}\text { DIVERSITY OF } \\
\text { OPINION }\end{array}$ & $\begin{array}{l}\text { COMMUNITY } \\
\text { NEWS }\end{array}$ & $\begin{array}{c}\text { MULTI- } \\
\text { CULTURALISM }\end{array}$ & ADVERTISING \\
\hline VOICES & $\begin{array}{c}0.0767^{* * * *} \\
(0.0263)\end{array}$ & $\begin{array}{l}0.0491^{*} \\
(0.0270)\end{array}$ & $\begin{array}{l}0.1120^{* * *} \\
(0.0230)\end{array}$ & $\begin{array}{l}0.0445^{\text {**** }} \\
(0.0257)\end{array}$ \\
\hline VOICES $\times S T A T I O N S$ & $\begin{array}{l}-0.0011 \\
(0.0011)\end{array}$ & $\begin{array}{l}-0.0018^{* * *} \\
(0.0008)\end{array}$ & $\begin{array}{l}-0.0015^{*} \\
(0.0008)\end{array}$ & $\begin{array}{l}-0.001 \\
(0.0008)\end{array}$ \\
\hline STATIONS & $\begin{array}{l}-0.0195 \\
(0.0161)\end{array}$ & $\begin{array}{c}0.0006 \\
(0.0167)\end{array}$ & $\begin{array}{l}-0.0414^{* * *} \\
(0.0147)\end{array}$ & $\begin{array}{l}-0.0007 \\
(0.0142)\end{array}$ \\
\hline$A G E$ & $\begin{array}{l}0.0396^{* * * *} \\
(0.0098)\end{array}$ & $\begin{array}{l}0.0928^{* * * *} \\
(0.0109)\end{array}$ & $\begin{array}{c}0.0252^{* *} \\
(0.0103)\end{array}$ & $\begin{array}{c}0.111^{* * *} \\
(0.0101)\end{array}$ \\
\hline$E D U C$ & $\begin{array}{c}0.141^{* * *} \\
(0.0164)\end{array}$ & $\begin{array}{l}0.0824^{* * *} \\
(0.0195)\end{array}$ & $\begin{array}{l}0.1240^{* * * *} \\
(0.0157)\end{array}$ & $\begin{array}{l}0.0999^{* * *} \\
(0.0191)\end{array}$ \\
\hline GENDER & $\begin{array}{l}-0.0397 \\
(0.0295)\end{array}$ & $\begin{array}{l}0.1310^{* * *} \\
(0.0303)\end{array}$ & $\begin{array}{c}0.0523^{*} \\
(0.0301)\end{array}$ & $\begin{array}{c}0.0196 \\
(0.0250)\end{array}$ \\
\hline INCOME & $\begin{array}{l}0.0574^{* * *} \\
(0.0124)\end{array}$ & $\begin{array}{l}-0.0022 \\
(0.0122)\end{array}$ & $\begin{array}{l}-0.0300^{* *} \\
(0.0152)\end{array}$ & $\begin{array}{c}0.0295^{* *} \\
(0.0117)\end{array}$ \\
\hline$R A C E$ & $\begin{array}{c}0.0623^{*} \\
(0.0334)\end{array}$ & $\begin{array}{l}-0.1210^{* * * *} \\
(0.0366)\end{array}$ & $\begin{array}{l}-0.0788^{*} \\
(0.0406)\end{array}$ & $\begin{array}{l}0.2210^{* * * *} \\
(0.0380)\end{array}$ \\
\hline$\hat{\lambda}_{m}$ & $\begin{array}{l}-0.0550^{* *} \\
(0.0260)\end{array}$ & $\begin{array}{l}-0.0250 \\
(0.0170)\end{array}$ & $\begin{array}{l}-0.0540^{* * *} \\
(0.0210)\end{array}$ & $\begin{array}{c}0.0074 \\
(0.0166)\end{array}$ \\
\hline Likelihood & $-4,844.4$ & $-5,218.4$ & $-5,182.8$ & $-4,910.8$ \\
\hline \multicolumn{5}{|c|}{ Mean change in predicted } \\
\hline \multicolumn{5}{|l|}{ probabilities } \\
\hline$\Delta P_{L} / \Delta X$ & 0.0159 & 0.0084 & 0.0342 & 0.0066 \\
\hline$\Delta P_{M} / \Delta X$ & 0.0031 & -0.0003 & -0.0116 & 0.0053 \\
\hline$\Delta P_{H} / \Delta X$ & -0.0190 & -0.0081 & -0.0226 & -0.0119 \\
\hline
\end{tabular}

NOTES. Estimated by weighted maximum likelihood. Bootstrapped standard errors in parentheses. ${ }^{* * * *}$ denotes significant at the one percent level. ${ }^{* * *}$ denotes significant at the five percent level. ${ }^{*}$ denotes significant at the ten percent level. Estimated cutoff parameters and estimated parameters for the media alternative dummy variables are not reported. Number of observations is 5,102. Sample mean probabilities are calculated from each individual respondent's predicted probabilities. $\Delta P_{L}=P_{L 1}-P_{L 0}, \Delta P_{M}=P_{M I}-P_{M 0}, \Delta P_{H}=P_{H 1}-P_{H 0}$, and $\triangle X=\triangle V O I C E S=-1$. 
Table 11. Impact on Consumer Welfare From a Change in Market Structure

\begin{tabular}{|c|c|c|c|c|c|c|c|c|c|c|c|}
\hline Size & $\begin{array}{l}\text { Pop. } \\
\text { Share }\end{array}$ & DIV & MCULT & ADV & CNEWS & DIV & MCULT & ADV & CNEWS & Total & $\begin{array}{c}\text { Total less } \\
\text { ADV }\end{array}$ \\
\hline & & \multicolumn{4}{|c|}{$\frac{\text { Average consumer welfare per month }}{\text { (Dollars per month) }}$} & \multicolumn{6}{|c|}{$\frac{\text { Annual aggregate welfare in market }}{\text { (Dollars in millions) }}$} \\
\hline 5 & 0.050 & $\begin{array}{l}-0.61 \\
(0.05)\end{array}$ & $\begin{array}{l}-0.23 \\
(0.07)\end{array}$ & $\begin{array}{c}0.30 \\
(0.04)\end{array}$ & $\begin{array}{l}-0.45 \\
(0.03)\end{array}$ & $\begin{array}{l}-32.87 \\
(2.87)\end{array}$ & $\begin{array}{l}-12.58 \\
(3.60)\end{array}$ & $\begin{array}{l}16.49 \\
(2.13)\end{array}$ & $\begin{array}{l}-24.40 \\
(1.67)\end{array}$ & -53.36 & -69.85 \\
\hline 6 & 0.061 & $\begin{array}{l}-0.59 \\
(0.07)\end{array}$ & $\begin{array}{l}-0.22 \\
(0.09)\end{array}$ & $\begin{array}{c}0.29 \\
(0.05)\end{array}$ & $\begin{array}{l}-0.42 \\
(0.04)\end{array}$ & $\begin{array}{l}-38.84 \\
(4.36)\end{array}$ & $\begin{array}{l}-14.72 \\
(5.69)\end{array}$ & $\begin{array}{l}19.19 \\
(3.36)\end{array}$ & $\begin{array}{l}-27.51 \\
(2.44)\end{array}$ & -61.87 & -81.06 \\
\hline 7 & 0.091 & $\begin{array}{l}-0.59 \\
(0.06)\end{array}$ & $\begin{array}{l}-0.23 \\
(0.07)\end{array}$ & $\begin{array}{c}0.29 \\
(0.04)\end{array}$ & $\begin{array}{l}-0.40 \\
(0.03)\end{array}$ & $\begin{array}{l}-57.83 \\
(5.57)\end{array}$ & $\begin{array}{l}-22.67 \\
(7.20)\end{array}$ & $\begin{array}{l}28.55 \\
(3.91)\end{array}$ & $\begin{array}{l}-39.29 \\
(2.84)\end{array}$ & -91.24 & -119.8 \\
\hline 8 & 0.081 & $\begin{array}{l}-0.57 \\
(0.06)\end{array}$ & $\begin{array}{l}-0.22 \\
(0.07)\end{array}$ & $\begin{array}{c}0.28 \\
(0.04)\end{array}$ & $\begin{array}{l}-0.37 \\
(0.03)\end{array}$ & $\begin{array}{r}-49.66 \\
(4.99)\end{array}$ & $\begin{array}{c}-19.47 \\
(6.11)\end{array}$ & $\begin{array}{l}24.49 \\
(3.57)\end{array}$ & $\begin{array}{l}-32.84 \\
(2.36)\end{array}$ & -77.47 & -102.0 \\
\hline 9 & 0.095 & $\begin{array}{l}-0.54 \\
(0.05)\end{array}$ & $\begin{array}{l}-0.21 \\
(0.07)\end{array}$ & $\begin{array}{c}0.27 \\
(0.04)\end{array}$ & $\begin{array}{l}-0.35 \\
(0.03)\end{array}$ & $\begin{array}{r}-55.97 \\
(5.46)\end{array}$ & $\begin{array}{l}-21.94 \\
(7.28)\end{array}$ & $\begin{array}{l}28.06 \\
(4.30)\end{array}$ & $\begin{array}{l}-36.21 \\
(2.76)\end{array}$ & -86.06 & -114.1 \\
\hline 10 & 0.056 & $\begin{array}{l}-0.55 \\
(0.06)\end{array}$ & $\begin{array}{l}-0.21 \\
(0.09)\end{array}$ & $\begin{array}{c}0.27 \\
(0.04)\end{array}$ & $\begin{array}{l}-0.34 \\
(0.03)\end{array}$ & $\begin{array}{r}-33.08 \\
(3.91)\end{array}$ & $\begin{array}{l}-12.90 \\
(5.30)\end{array}$ & $\begin{array}{l}16.20 \\
(2.69)\end{array}$ & $\begin{array}{l}-20.59 \\
(1.75)\end{array}$ & -50.38 & -66.57 \\
\hline 11 & 0.099 & $\begin{array}{l}-0.53 \\
(0.05)\end{array}$ & $\begin{array}{l}-0.21 \\
(0.06)\end{array}$ & $\begin{array}{c}0.26 \\
(0.03)\end{array}$ & $\begin{array}{l}-0.32 \\
(0.02)\end{array}$ & $\begin{array}{r}-57.29 \\
(5.49)\end{array}$ & $\begin{array}{c}-22.36 \\
(6.76)\end{array}$ & $\begin{array}{l}28.33 \\
(3.70)\end{array}$ & $\begin{array}{l}-34.51 \\
(2.29)\end{array}$ & -85.83 & -114.2 \\
\hline 12 & 0.069 & $\begin{array}{l}-0.52 \\
(0.06)\end{array}$ & $\begin{array}{l}-0.20 \\
(0.08)\end{array}$ & $\begin{array}{c}0.25 \\
(0.04)\end{array}$ & $\begin{array}{l}-0.30 \\
(0.03)\end{array}$ & $\begin{array}{r}-38.83 \\
(4.23)\end{array}$ & $\begin{array}{r}-15.00 \\
(5.63)\end{array}$ & $\begin{array}{l}18.40 \\
(2.80)\end{array}$ & $\begin{array}{l}-22.13 \\
(1.89)\end{array}$ & -57.57 & -75.97 \\
\hline 13 & 0.024 & $\begin{array}{l}-0.51 \\
(0.09)\end{array}$ & $\begin{array}{l}-0.20 \\
(0.12)\end{array}$ & $\begin{array}{c}0.24 \\
(0.06)\end{array}$ & $\begin{array}{l}-0.28 \\
(0.03)\end{array}$ & $\begin{array}{r}-13.31 \\
(2.34)\end{array}$ & $\begin{array}{l}-5.12 \\
(3.07)\end{array}$ & $\begin{array}{c}6.31 \\
(1.44)\end{array}$ & $\begin{array}{l}-7.31 \\
(0.88)\end{array}$ & -19.43 & -25.74 \\
\hline 14 & 0.093 & $\begin{array}{l}-0.47 \\
(0.05)\end{array}$ & $\begin{array}{l}-0.17 \\
(0.06)\end{array}$ & $\begin{array}{c}0.24 \\
(0.03)\end{array}$ & $\begin{array}{l}-0.26 \\
(0.02)\end{array}$ & $\begin{array}{r}-47.76 \\
(4.64)\end{array}$ & $\begin{array}{r}-17.06 \\
(6.43)\end{array}$ & $\begin{array}{l}23.77 \\
(3.14)\end{array}$ & $\begin{array}{l}-26.01 \\
(1.80)\end{array}$ & -67.05 & -90.83 \\
\hline 15 & 0.03 & $\begin{array}{l}-0.48 \\
(0.08)\end{array}$ & $\begin{array}{l}-0.18 \\
(0.12)\end{array}$ & $\begin{array}{c}0.22 \\
(0.05)\end{array}$ & $\begin{array}{l}-0.24 \\
(0.03)\end{array}$ & $\begin{array}{r}-15.57 \\
(2.74)\end{array}$ & $\begin{array}{l}-5.99 \\
(3.77)\end{array}$ & $\begin{array}{c}7.24 \\
(1.70)\end{array}$ & $\begin{array}{l}-7.72 \\
(1.00)\end{array}$ & -22.04 & -29.28 \\
\hline 16 & 0.079 & $\begin{array}{l}-0.45 \\
(0.05)\end{array}$ & $\begin{array}{l}-0.16 \\
(0.07)\end{array}$ & $\begin{array}{c}0.23 \\
(0.03)\end{array}$ & $\begin{array}{l}-0.23 \\
(0.02)\end{array}$ & $\begin{array}{r}-38.73 \\
(4.62)\end{array}$ & $\begin{array}{r}-14.06 \\
(6.21)\end{array}$ & $\begin{array}{l}19.58 \\
(2.93)\end{array}$ & $\begin{array}{r}-19.41 \\
(1.55)\end{array}$ & -52.62 & -72.20 \\
\hline 17 & 0.072 & $\begin{array}{l}-0.45 \\
(0.06)\end{array}$ & $\begin{array}{l}-0.16 \\
(0.08)\end{array}$ & $\begin{array}{c}0.21 \\
(0.03)\end{array}$ & $\begin{array}{l}-0.20 \\
(0.02)\end{array}$ & $\begin{array}{r}-34.85 \\
(4.29)\end{array}$ & $\begin{array}{r}-12.56 \\
(6.10)\end{array}$ & $\begin{array}{l}16.45 \\
(2.72)\end{array}$ & $\begin{array}{r}-15.83 \\
(1.39)\end{array}$ & -46.79 & -63.24 \\
\hline 18 & 0.043 & $\begin{array}{l}-0.45 \\
(0.07)\end{array}$ & $\begin{array}{l}-0.17 \\
(0.10)\end{array}$ & $\begin{array}{c}0.21 \\
(0.05)\end{array}$ & $\begin{array}{l}-0.19 \\
(0.02)\end{array}$ & $\begin{array}{r}-21.00 \\
(3.38)\end{array}$ & $\begin{array}{l}-8.03 \\
(4.71)\end{array}$ & $\begin{array}{c}9.67 \\
(2.19)\end{array}$ & $\begin{array}{l}-8.74 \\
(1.05)\end{array}$ & -28.10 & -37.77 \\
\hline 19 & 0.026 & $\begin{array}{l}-0.44 \\
(0.08)\end{array}$ & $\begin{array}{l}-0.19 \\
(0.11)\end{array}$ & $\begin{array}{c}0.21 \\
(0.05)\end{array}$ & $\begin{array}{l}-0.17 \\
(0.02)\end{array}$ & $\begin{array}{r}-12.44 \\
(2.23)\end{array}$ & $\begin{array}{l}-5.35 \\
(3.17)\end{array}$ & $\begin{array}{c}5.90 \\
(1.43)\end{array}$ & $\begin{array}{l}-4.87 \\
(0.60)\end{array}$ & -16.76 & -22.66 \\
\hline 20 & 0.032 & $\begin{array}{l}-0.38 \\
(0.03)\end{array}$ & $\begin{array}{c}-0.14 \\
(0.04)\end{array}$ & $\begin{array}{c}0.17 \\
(0.02)\end{array}$ & $\begin{array}{l}-0.09 \\
(0.01)\end{array}$ & $\begin{array}{r}-13.26 \\
(1.01)\end{array}$ & $\begin{array}{c}-4.98 \\
(1.50)\end{array}$ & $\begin{array}{c}5.93 \\
(0.62)\end{array}$ & $\begin{array}{l}-3.20 \\
(0.19)\end{array}$ & -15.51 & -21.44 \\
\hline Total & 1 & $\begin{array}{l}-0.52 \\
(0.01)\end{array}$ & $\begin{array}{l}-0.20 \\
(0.01)\end{array}$ & $\begin{array}{c}0.25 \\
(0.01)\end{array}$ & $\begin{array}{l}-0.31 \\
(0.01)\end{array}$ & $\begin{array}{l}-561.3 \\
(15.35)\end{array}$ & $\begin{array}{l}-214.8 \\
(15.35)\end{array}$ & $\begin{array}{c}274.6 \\
(10.46)\end{array}$ & $\begin{array}{l}-330.6 \\
(6.82)\end{array}$ & -832.1 & $-1,107$ \\
\hline
\end{tabular}

NOTES. Bootstrapped standard errors in parentheses. The change in market structure is a one-unit reduction in the number of independent TV voices in the market, all other things held constant. There are 90,193,905 population households in markets from five to 20 TV stations (FCC, 2011). Pop. share is the number of population households in the market divided by population households.

DIV is diversity of opinion in the reporting of information, MCULT is coverage of multiculturalism issues, ADV is amount of space or time devoted to advertising, and CNEWS is amount of information on community news and events. Total losses of $\$ 832.1$ million are the sum of the individual market losses. 


\section{Figure 1. Change in Average Consumer Welfare Per Month From a Change in Market Structure}

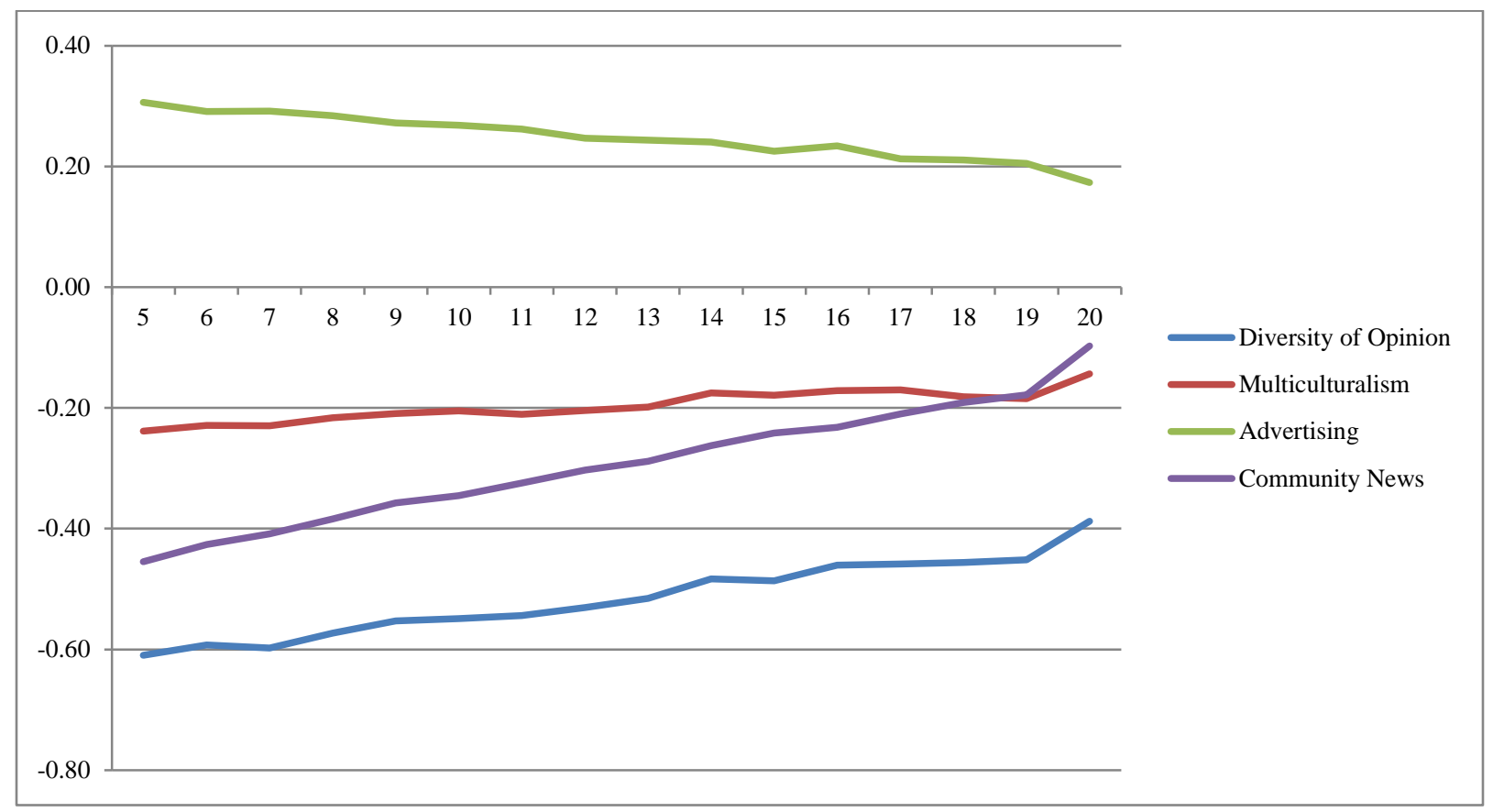

NOTES. Vertical axis is dollars per month and horizontal axis is number of TV stations. The change in market structure is a one-unit reduction in the number of independent TV voices in the market, all other things held constant.

SOURCE. Table 11. 